\title{
SOBRE EL ORDEN DE PALABRAS EN GRIEGO: EL GENITIVO ADNOMINAL *
}

\begin{abstract}
The aim of this paper is to show that the relative order of Genetive and governing noun is determined, at least in Attic litterary prose of $c a .400$ B. C., by a syntactic rule, according to which, Ablative or Partitive Genetive follows the main noun, and Possessive Genetive goes before the modified noun. A selection from Lysias, Thucydides, Antiphon, Andocides, and Pseudo-Xenophon's Resp. Ath. has been taken into account for the purpose. The syntactic determination of Greek word order being at any case taken for granted, a set of lexical rules is previously established in order to give a sounder account of the evidence; in the author's view, the disproving instances are due either to emphatic reasons or to the overlapping of two rules. A second class of lexical rules can be inferred from the position of the article. May the proposed syntactic rule be right, Classical Greek is a VO language as well a OV one.
\end{abstract}

1. El orden de palabras ha sido tradicionalmente uno de los aspectos más descuidados en el estudio de la lengua griega ${ }^{1}$. A este desinterés han contribuido razones de diversa índole: por un lado, la consideración de que las desinencias morfológicas expresan de por sí las relaciones sintácticas, dentro de un orden de palabras que, simplistamente, se califica de libre, sin más; por otro lado, la dificultad de reunir material abundante para someterlo a una elaboración estadística; y, finalmente, la idea de que en la mayoría de las frases el orden de palabras obedece a una intención estilística exclusivamente. Por

* Agradezco a los profesores M. S. Ruipérez y C. García Gual las críticas y sugerencias que me han hecho para mejorar determinados puntos de este trabajo.

1 Para una introducción general (con la bibliografía anterior a 1960), K. J. Dover, Greek Word Order, Cambridge 1968. Hay que mencionar además J. Palm, Zur Funktion und Stellung des attributiven Demonstrativums im Griechischen, Lund 1960; L. Bergson, Zur Stellung des Adjektivs in der älteren griechischen Prosa, Upsala 1960; F. Brunel, La construction de l'adjectif dans les groupes nominaux du grec, Paris 1964. 
estas razones, la bibliografía dedicada al tema es reducida en comparación con la consagrada a otras partes de la lengua griega. Sin embargo, en los últimos años el interés por el orden de palabras ha ido en aumento, tanto en lo que se refiere a las lenguas clásicas, como en la descripción de otras lenguas ${ }^{2}$. Aun así, la necesidad de trabajos sobre este tema es notoria.

2. En primer lugar, conviene precisar algunos criterios de orden práctico y metodológico. Los datos utilizados son todos los genitivos

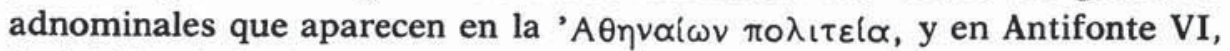
Andócides I, Lisias I, III, XII, XXIV, y Tucídides VI. Esto quiere decir que nuestro enfoque es sincrónico, y que tratamos de describir el orden del genitivo adnominal con respecto al regente circa 400 a. C. en el dialecto ático. La elección de obras o fragmentos que pertenecen a autores y géneros diferentes presenta ciertas ventajas con respecto a la utilización de un corpus de datos más homogéneo: permitirá mostrar que el orden de palabras que observemos no es el producto de la preferencia individual de un solo autor, sino que existe un orden habitual compartido por los diferentes autores y géneros literarios escritos en prosa; además, se podrán observar las diferencias propias de cada autor, en el caso de que existan. Esto quiere decir que la finalidad del presente trabajo no es de carácter prioritariamente estilístico; en efecto, sólo cuando sea posible describir el orden regular de palabras, podremos observar, además de las diferencias entre autores y géneros literarios diferentes, las desviaciones estilísticas, atribuibles, bien a la elección individual de un autor, bien a hechos contextuales.

2 El punto de partida está constituido por J. H. Greenberg, «Some Universals of Grammar with Particular Reference to the Order of Meaningful Elements», en Universals of Language, ed. J. H. Greenberg, Cambridge Mass. 1966, pp. 73-113. E1 método de los cuasi-universales lingüísticos se ha aplicado desde entonces, sobre todo, a la reconstrucción del indoeuropeo: W. P. Lehmann, Proto-Indo-European Syntax, Austin 1974; P. Friedrich, Proto-Indo-European Syntax: The Order of Meaningful Elements (JIES Monographs 1), 1975; W. P. Lehmann, «A Discussion of Compound and Word Order», en Word Order and Word Order Change, ed. Ch. N. Li, Austin 1975, p. 151 ss.; J. L. Houben, JIES 5, 1977, p. 1 ss.; W. Dressler, KZ 83, 1968, p. 1 ss.; KZ 87, 1973, p. 5 ss. Para el griego: H. B. Rosén, Die Sprache 21, 1975, p. 22 ss.; para el micénico: Y. Duhoux, Minos 14, 1975, p. 123 ss. Cf. igualmente L. Rubio, Introducción a la sintaxis estructural del latín II, Barcelona 1976, p. 13 ss.; H. Contreras, El orden de palabras en español, trad. esp., Madrid 1978. Diversos estudios que se refieren a otras lenguas se recogen en Word Order and Word Order Change citado más arriba. Más recientes son J. Aitchison, TPhS 1979, pp. 43-65, con extensa bibliografía; Syntactic Typology, ed. W. P. Lehmann, The University Texas Press, 1978. 
Los ejemplos recogidos suman en total 1.185; hay que señalar que, aunque existan algunos errores en el recuento de los datos (sobre todo en algunos ejemplos en los que un genitivo puede ser considerado adverbal o adnominal), éstos han de ser mínimos y de ningún modo podrán desfigurar las conclusiones.

Así, pues, la finalidad del presente trabajo está triplemente limitada: el genitivo adnominal, en el dialecto ático de circa 400 a. C., según se documenta en la prosa literaria. A pesar de estas limitaciones, creemos que sólo mediante trabajos parciales previos se podrá llegar a una descripción general y sistemática del orden de palabras en griego, que comprenda todas las épocas de la historia de la lengua y todos los dialectos.

3. La presunción esencial de la que debe partir cualquier trabajo sobre el orden de palabras es la de que en la frase griega los elementos no se ordenan de un modo arbitrario, sino que existe un orden habitual en su aparición a lo largo de la cadena hablada. Hechos de diversa índole justifican esta presunción. En primer lugar, si bien cualquier examen somero de una página de texto griego permite comprobar que el orden de los elementos no es uniforme, sin embargo tampoco se puede negar que determinados sintagmas al menos manifiestan cierta regularidad en cuanto al orden de sus elementos ${ }^{3}$. Por otro lado, para algunos grupos de palabras el orden es fijo dentro de la frase: las enclíticas ocupan regularmente el segundo lugar ${ }^{4}$; las negaciones suelen comenzar la frase desde el indoeuropeo ${ }^{5}$; también los interrogativos encabezan la oración ${ }^{6}$, al igual que el pronombre relativo y las conjunciones de subordinación ${ }^{7}$. De la misma manera, las oraciones de relativo, la mayoría de las oraciones subordinadas y los infinitivos suelen ir al final de la frase ${ }^{8}$. Para otros elementos de la frase, el orden

\footnotetext{
3 Algunos ejemplos en Schwyzer, II, p. 691 ss.; Meillet-Vendryes 2 , p. 578 ss.; y, sobre todo, en H. Frisk, Studien zur griechischen Wortstellung, Gotemburgo 1932; A. Loepfe, Die Wortstellung im griechischen Sprachsatz erklärt an Stücken aus Platon und Menander, Freiburg i. d. Sch. 1940.

4 J. Wackernagel, IF 1, 1892, p. 333 s. (= Kleine Schriften I, Göttingen 1953, p. 1 ss.); E. Fraenkel, NGG 1932, p. 197 ss.; 1933, p. 319 ss. (= Kleine Beiträge zur klassischen Philologie, Roma 1964, p. 73 ss.); Sitzungsber. Bayer. Akad. Philos.-Hist. Kl., 1965, H. 2.

5 Cf. J. Wackernagel, Vorlesungen, II, p. 248 s.

6 Cf. Schwyzer, II, p. 213; para los ejemplos contrarios, G. Thomson, CQ 33, 1939 , p. 147 ss.

$7 \mathrm{La}$ inversión es frecuente en Píndaro y está causada por motivos claramente estilísticos, cf. S. Lauer, Zur Wortstellung bei Pindar, Winterthur 1959.

8 Cf., por ejemplo, P. Monteil, La phrase relative en grec ancien, París 1963, p. 29, passim.
} 
de palabras regular es más problemático: así, en lo que se refiere al orden objeto-verbo o verbo-objeto existen opiniones contrapuestas entre los estudiosos 9 . En definitiva, no está injustificada la presunción inicial de que existe un orden de palabras habitual en todos los elementos que componen la frase griega.

Sin embargo, ningún hecho justifica la idea de que el orden de palabras ha permanecido inalterable a lo largo de la historia de la lengua griega; por el contrario, a juzgar por lo que ha acontecido en otras lenguas no emparentadas con el griego ${ }^{10}$, en el curso de su historia ha habido alteraciones profundas en la ordenación de los elementos de la frase. Incluso dentro del griego se han observado hechos semejantes". Por estas razones, un enfoque sincrónico, como el que aquí se pretende en principio hacer, evita los riesgos inherentes a la comparación entre autores y obras de época diferente. Es posible, sin embargo, que en la ordenación de los elementos de la frase de la prosa ática de circa 400 a. C. subsistan restos y arcaísmos procedentes de otros sistemas de época anterior a la que aquí es objeto de consideración.

Del mismo modo, tampoco existe ningún hecho que justifique la idea de que el orden de palabras haya sido idéntico en todos los dialectos griegos (y consiguientemente en todos los géneros literarios); por esta causa, es preferible restringir el objeto de estudio a lo que se refiere a un dialecto único $\mathrm{y}$, en un segundo momento, comparar las conclusiones establecidas para un dialecto con lo que sucede en otros. En este sentido, la elección del ático como punto de partida parece lo más apropiado, porque la documentación es más extensa ${ }^{12}$.

$9 \mathrm{El}$ orden SVO es el habitual para E. Kieckers, Die Stellung des Verbs im Griechischen und in den verwandten Sprachen, I, Estrasburgo 1911; Meillet -Vendryes $_{2}$, p. 581; por el contrario, es regular SOV para P. Fischer, Glotta 13, 1924, p. 1 ss.; 189 ss.; H. Frisk, op. cit., p. 14 ss. (en oración principal declarativa); p. 27 ss. (en oración subordinada).

10 Cf. Word Order and Word Order Change, passim.

11 Para las inscripciones cretenses, K. Meister, $I F$ 18, 1906, p. 133 ss. (esp. 201 s.) ha observado que el genitivo partitivo precede, en general, al nombre regente en las más antiguas, mientras que en las más recientes va detrás; el genitivo comparativo suele seguir al regente; el posesivo sigue al regente con o sin repetición del artículo del nombre regente. El examen de las inscripciones áticas del siglo $\mathrm{v}$ no conduce a conclusiones claras según R. Müller, Philologus 64, 1905, p. 554 ss.

12 Aunque las inscripciones áticas contemporáneas de los datos analizados aquí no han sido tenidas en cuenta, una consideración somera de los ejemplos recogidos por Müller, loc. cit., muestra ciertas diferencias con respecto a los datos de la prosa literaria, sobre todo en lo que se refiere al uso del artículo del nombre regente (cf. $\S 6$ y $\S 7$ ). Como los ejemplos de la propia prosa literaria muestran que estas diferencias deben interpretarse de manera diacrónica (cf. 6.2; § 9), hay 
4. El problema inicial en el momento de comenzar un estudio sobre el orden de palabras es que a priori es imposible tener certeza sobre qué tipo de causa o causas determinan el orden de los elementos en la frase. En principio, pueden determinar el orden de palabras causas fonológicas, morfológicas, sintácticas, léxicas, estilísticas, lógicas, etc.; en una palabra, cualquier categoría lingüística o incluso extralinguiística ${ }^{13}$. Sabemos que en parte existen causas fonológicas (ley de Wackernagel), pero nada excluye que en griego causas de carácter diferente determinen el orden de los elementos de la frase. En general, se han buscado causas de orden lógico ${ }^{14}$, estilístico ${ }^{15}$ o sintáctico ${ }^{16}$; $\mathrm{y}$, en todo caso, es presunción generalizada la idea de que en griego el orden de palabras obedece fundamentalmente a causas sintácticas. Por eso es tradicional que el orden de palabras sea un capítulo incluido dentro de la sintaxis. Desde un punto de vista práctico, una descripción del orden de palabras griego basado en criterios morfológicos o sintácticos ofrece algunas ventajas: las categorías morfológicas y sintácticas son cerradas, a diferencia de lo que ocurre, por ejemplo, con las categorías léxicas, $\mathrm{y}$, por tanto, las conclusiones establecidas mediante estos criterios son verificables y controlables con mayor facilidad.

Sin embargo, una primera aproximación basada en criterios léxicos ofrece una importante ventaja de orden metodológico: permite clasificar los datos, al menos en un principio, de un modo más aséptico; igualmente, permite diferenciar de modo tajante qué son datos observados en el texto y qué son conclusiones obtenidas a partir de aquellos datos. Por esta causa, el objetivo inicial del presente trabajo es enunciar una serie de reglas parciales léxicas para aquellos sintagmas de nombre-genitivo adnominal o viceversa que muestran un orden de pala-

buenas razones para pensar que las discrepancias entre inscripciones $\mathbf{y}$ prosa literaria son producto del carácter oficial y arcaizante de aquéllas. Por tanto, no representan un estadio sincrónico con el que documenta la prosa literaria.

13 Cf. Dover, op. cit., p. 3 ss.

14 Cf. A. Loepfe, op. cit., p. 23 ss., que aplica sistemáticamente los términos «rema» (= predicado psicológico, núcleo de la comunicación) y «tema» (= sujeto psicológico, base de la comunicación o elemento que el oyente puede predecir); Dover, op. cit., p. 34 ss.; la misma distinción usa H. Contreras, op. cit., recientemente, para el estudio del orden de palabras en español.

15 Véase, para la bibliografía, Dover, op. cit., p. 66 ss.; Frisk, op. cit., p. 5 ss. y, sobre todo, A. Loepfe, op. cit., p. 1 ss.

16 Habitualmente se entiende por «orden sintáctico habitual» orden heredado del indoeuropeo o, al menos, antiguo en la lengua, mientras que el orden anómalo resultaría de una innovación; cf. A. Loepfe, op. cit., p. 1 ss. Aunque en este trabajo se trata de establecer una hipótesis de determinación sintáctica del orden de palabras (cf. § 11), por supuesto, no es éste el sentido en el que se usa aquí «orden sintáctico habitual»: cf. infra.

XLIX, $1.0^{\circ}-8$ 
bras único, o al menos muy habitual. A partir de estos ejemplos trataremos de obtener conclusiones progresivamente más generales; es decir, intentaremos reducir las categorías léxicas a categorías sintácticas.

Es preciso señalar que, en pocos ejemplos dentro de estas reglas parciales léxicas, se podrá observar un orden de palabras único; lo más frecuente, por el contrario, es que en un sintagma determinado el orden de palabras sea predominantemente regente-genitivo o bien genitivo-regente. Esta circunstancia, sin embargo, no indica que no existan reglas respetadas en la ordenación de los elementos; antes bien, muestra que existe una ordenación habitual, que sería la posición no marcada, y una ordenación anómala de los elementos de la frase, que correspondería al término marcado de una oposición privativa. Parece razonable pensar que el orden irregular obedece a una causa estilística o enfática, que, aunque en algunos casos resulta imperceptible, es evidente en la mayoría de los ejemplos. No obstante, para no alargar en exceso este trabajo, será suficiente comentar sólo algunos ejemplos particularmente significativos.

5. De acuerdo, pues, con lo dicho, trataremos de enunciar en primer lugar una serie de reglas léxicas parciales (§§ 5-7); es decir, intentaremos mostrar, mediante una clasificación puramente léxica, que existe un orden habitual, al menos en determinados ejemplos. Dos advertencias son necesarias antes de proceder a la presentación de los datos: por un lado, con el fin de lograr una mayor claridad en la exposición, es preferible por el momento hacer abstracción de la ausencia, presencia o repetición del artículo del nombre regente; los datos que a él se refieren serán presentados más adelante (§§ 6-7). Por otro lado, sería poco prudente considerar regular y habitual el orden que presentan los grupos de genitivo-regente o viceversa que aparecen una sola vez en los datos recogidos; por eso, es preferible reservar su inclusión para más adelante ( $(10)$. En las listas siguientes se han incluido los ejemplos que aparecen al menos tres veces en los datos analizados. Igualmente, dejaremos para más adelante ( $\S \S 9-10)$ aquellos ejemplos que, aun siendo numerosos en los datos, presentan ciertas irregularidades que merecen una discusión especial.

5.1 Una serie de palabras manifiesta una clara tendencia a aparecer detrás del genitivo que rigen. Son éstas las siguientes en las obras cuyos datos han sido recogidos aqui: 


\begin{tabular}{|c|c|c|c|c|}
\hline & Regentes & Regente-regido & $\begin{array}{c}\text { Tipo of voرol } \\
\text { of } \Sigma \delta \lambda \omega v o s\end{array}$ & Regido-regente \\
\hline 1. & $\not \xi \xi\llcorner\circ$ & 6 & & 18 \\
\hline 2. & $\alpha\lfloor\tau$ เos & 1 & & 14 \\
\hline 3. & $\delta(\mathrm{kn}$ & 2 & & 6 \\
\hline 4. & $\lambda$ óyos & 6 & 1 & 11 \\
\hline 5. & w & 1 & 4 & 9 \\
\hline 6. & \&pety & 1 & & 9 \\
\hline 7. & $\theta u \gamma d \tau \eta p$ & 1 & & 10 \\
\hline 8. & uńvuois & 0 & & 3 \\
\hline 9. & Epyor & 1 & & 7 \\
\hline 10. & $\xi \dot{u} \mu \mu \alpha \chi \circ \varsigma$ & 2 & & 3 \\
\hline 11. & $\pi \circ \lambda เ \tau \varepsilon l \alpha$ & 0 & & 3 \\
\hline 12. & 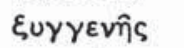 & 1 & & 5 \\
\hline 13. & $\pi o v \eta p l \alpha$ & 1 & & 8 \\
\hline 14. & $\mu \alpha \rho^{\prime} \tau \rho$ & 1 & & 13 \\
\hline 15. & olxla & 1 & 6 & 5 \\
\hline 16. & youń & 1 & & 3 \\
\hline 17. & $\sigma \hat{\omega} \mu \alpha$ & 1 & 3 & 2 \\
\hline 18. & voùs & 2 & & 3 \\
\hline 19. & $\gamma \hat{\eta}$ & 1 & 1 & 4 \\
\hline 20. & $x \rho \eta \mu \alpha \tau \alpha$ & 4 & 1 & 2 \\
\hline 21. & $\gamma \nu \omega \mu \eta$ & 5 & & 3 \\
\hline 22. & $\alpha \delta \varepsilon \lambda \phi \delta \varsigma$ & 5 & & 4 \\
\hline 23. & $\tau \alpha \kappa \propto \kappa \alpha$ & 0 & & 3 \\
\hline 24. & $\kappa \propto \tau \& \lambda \cup \sigma เ \varsigma$ & 0 & & 3 \\
\hline 25. & $\pi 0 \lambda l \tau \eta s$ & 0 & 1 & 3 \\
\hline 26. & $\beta \omega \mu \eta$ & 0 & & 3 \\
\hline 27. & $\pi \delta \lambda_{1 \varsigma}$ & 5 & & 6 \\
\hline 28. & $\pi \varepsilon \rho$ เколт & 0 & & 4 \\
\hline 29. & $\phi(\lambda \circ \varsigma$ & 1 & 1 & 2 \\
\hline 30. & $\psi \| \phi i \sigma \mu \alpha$ & 0 & 2 & 2 \\
\hline 31. & $\pi \alpha \rho \alpha \vee \circ \mu \mid \alpha$ & 0 & & 3 \\
\hline 32. & $\pi \alpha \tau \rho / \varsigma$ & 0 & 2 & 2 \\
\hline
\end{tabular}

Se observa, pues, que al menos en los ejemplos que integran la lista anterior es posible reconocer una ordenación habitual de los elementos que componen el sintagma. Sin embargo, la regularidad del orden es aún mayor si se tiene en cuenta que cuando en un ejemplo concreto coinciden dos palabras que manifiestan idéntica tendencia a aparecer en primero o en segundo lugar, una de las dos ha de ser necesariamente una excepción frente al orden habitual. Lo mismo ocurre si el genitivo que depende de las palabras que componen la lista anterior es una de las palabras que en genitivo ocupa habitualmente el segundo lugar, es decir, está precedida por el regente. Además, en algunos otros 
ejemplos son evidentes causas de carácter contextual o enfático. De ambos modos se puede justificar un buen número de las excepciones a cada uno de los epígrafes recogidos en la lista precedente.

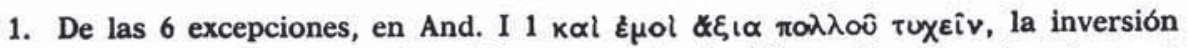
afecta tanto a $\measuredangle \xi ı, \alpha$, como al regido $\pi 0 \lambda \lambda$ ov (regla 68); en los dos ejemplos que

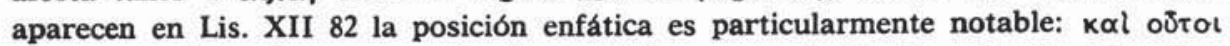

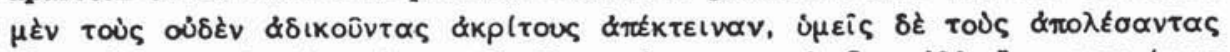

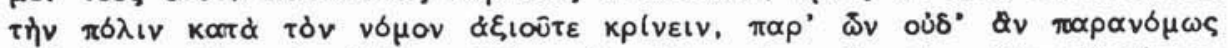

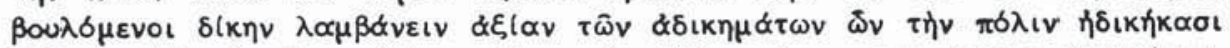

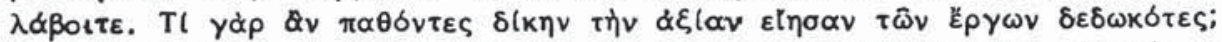

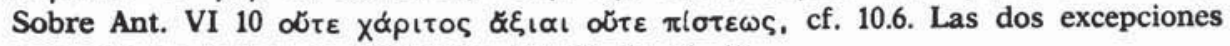
restantes se hallan en Tucídides (VI 21,$1 ; 64,1$ ).

Por el contrario, el adverbio correspondiente $\alpha \xi i \omega \varsigma$, al igual que los demás adverbios acompañados de un genitivo, precede siempre a su régimen (Tuc. VI 16, 2; 40, 2; etc.).

2. La única excepción en la que $\alpha$ trios precede a su genitivo es Lis. III 36 $\alpha(\tau$ lous $\tau \hat{\omega} \nu$ $\gamma \varepsilon \gamma \varepsilon \nu \eta \mu \varepsilon v \omega \omega v$; el participio sigue regularmente al regente (regla 34).

3. Las dos excepciones en las que $\delta l \mathrm{k} \eta$ precede a su régimen (Ant. VI $38 \mathrm{k} \alpha \mathrm{l}$

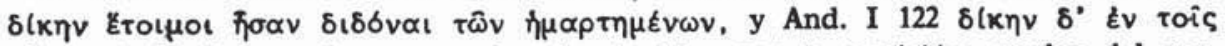

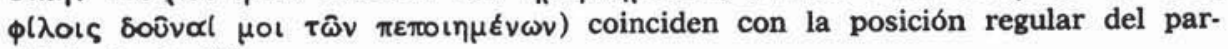
ticipio (regla 34 ).

4. De los 6 ejemplos en los que $\lambda$ óyos precede a su régimen, en 4 precede a un participio (Ant. VI 2, 18; And. I 55, 103) (regla 34); en Lis. XXIV 26 precede a đỡล̂v (regla 33); para el carácter especial de And. I 29, cf. MacDowell, ad loc. p. 83.

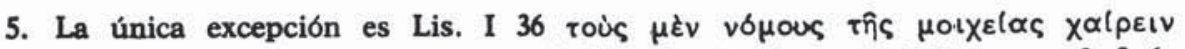

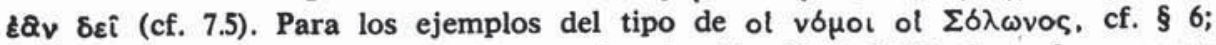
conviene observar, sin embargo, que en dos de ellos (And. I 82) el nombre regente va a su vez en genitivo (cf. Schwyzer, II, p. 135 s.; infra $6.2 ; 7.3 ; 10.3$ ).

6. La única excepción coincide con la posposición de un reflexivo contra la regla 69.

7. La única excepción coincide con la posposición de un reflexivo (Tuc. VI 59, 2).

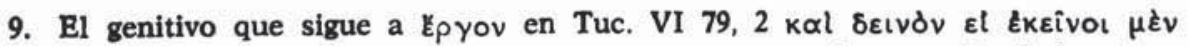

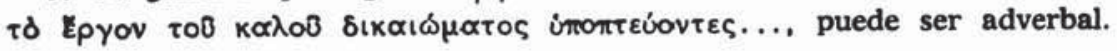

10. Las dos excepciones en las que $\xi_{u} \mu \mu \alpha \chi 0$ ○ precede a su régimen están causadas por el pronombre personal en genitivo (regla 33).

12. La excepción obedece a la posposición del pronombre personal (regla 33). 
13. La excepción obedece a la posposición del pronombre personal (regla 33).

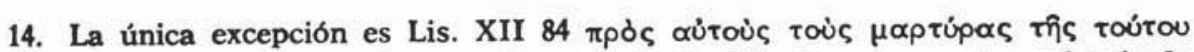

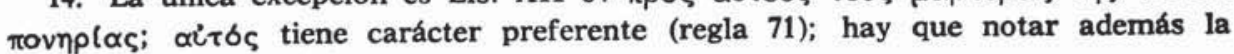
presencia de dos genitivos.

15. La única excepción en la que olkl $\alpha$ precede a su régimen es And. I 17, donde también aparecen dos genitivos (cf. 6.2, 7.3, 10.3).

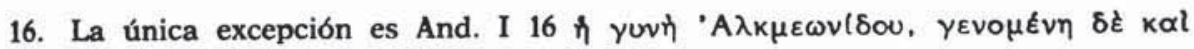

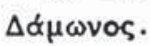

17. La única excepción (And. I 148) está causada por la posición regular del anaforico tras el regente (regla 33 ).

18. De las dos excepciones, en Tuc. VI 102, $3 \propto$ V̂िEৎ precede al genitivo del

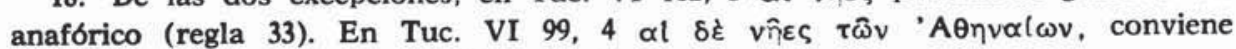
observar que el regido es partitivo (cf. § 9).

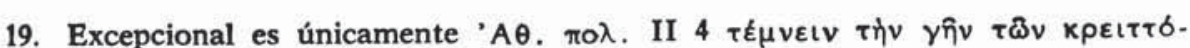
$v \omega v$; un orden de palabras igualmente excepcional en otro contexto aparece en

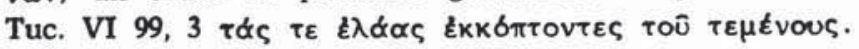

20. Aunque una pura consideración numérica de los datos induce a considerar el orden de palabras cuando el regente es $\chi \rho \nmid \mu \alpha \tau \alpha$ como libre, conviene incluir también estos ejemplos, porque las excepciones están causadas por la posición regular del participio en genitivo (And. I 95) o del pronombre anafórico (And. I

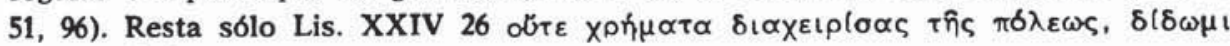

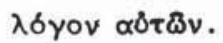

21. El regente $\gamma \nu \omega \mu \eta$ precede al genitivo que de él depende 5 veces; en 4 precede a un pronombre personal (regla 33); resta sólo Ant. VI 20 ákı ı́ $\delta^{\circ}$

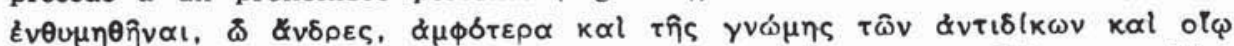

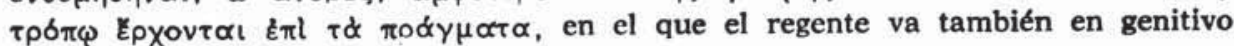
(cf. $6.2,7.3,10.3$ ).

22. De las cinco excepciones en las que $\langle\delta \varepsilon \lambda \phi \delta \varsigma$ precede al genitivo regido, en cuatro precede al genitivo de un pronombre personal o anafórico; resta sólo And. I 117.

27. En todas las excepciones en las que $\pi \delta \lambda_{1} \varsigma$ precede al genitivo regido, éste es un pronombre personal o anafórico (regla 33).

29. La única excepción en la que $\phi(\lambda \circ \varsigma$ precede al genitivo regido coincide con la colocación regular de un participio sustantivado en genitivo (And. I 53) (regla 34). 
5.2 Un segundo grupo de ejemplos en los que se puede observar un orden habitual lo componen las palabras que en genitivo suelen seguir al nombre regente:

\section{Regidos}

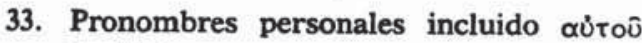
anafórico

34. Participios sustantivados en genitivo ...

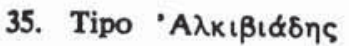

(১) $K \lambda \varepsilon เ v$ lov $\ldots . .$.

\section{Regente-regido}

$\begin{array}{rr}30 & 125 \\ 11 & 44 \\ 0 & 23\end{array}$

Como en el epígrafe anterior, un numeroso grupo de excepciones obedece a causas contextuales o a la coincidencia de dos palabras que suelen ocupar el segundo lugar en el mismo ejemplo.

33. De las 30 excepciones en las que un pronombre personal en genitivo precede a su regente, 8 pertenecen a las formas enclíticas del singular, colocadas ante el nombre del que dependen en segundo lugar de la frase (ley de Wackernagel) y 11 al genitivo del anafórico aútoû, también en segundo lugar de la frase; es

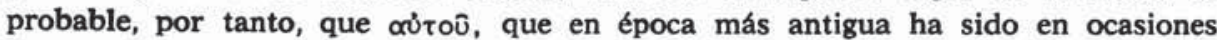
enclítico (cf. Schwyzer, p. 615), haya conservado en ocasiones la posición en la frase que era característica de las enclíticas.

En cuanto a las demás excepciones, en Lis. XII 50 y 61 la inversión del pronombre personal coincide con la posposición de évlots (en los datos recogidos

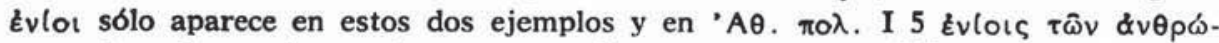
$\pi \omega v$; sin embargo, la semejanza con $\tau$ เ , hace pensar que también $\varepsilon v$ loı suele preceder al genitivo regido); en And. I 86 la posición irregular del pronombre personal coincide con la inversión de $\tau$ I $v \iota$ (regla 41); en And. I 57 y 104 coincide con la inversión de Ěkaotos (regla 43); igualmente, en Lis. III 14 y And. I 139 las

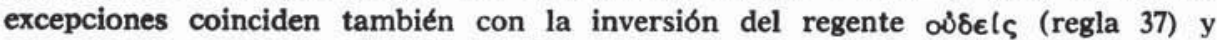
con la presencia de otras varias negaciones, circunstancia que permite asegurar

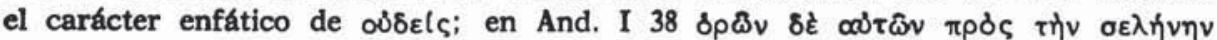
$\tau \nless \pi \rho \delta \sigma \omega \pi \alpha \tau \tilde{\tau} v \pi \lambda \varepsilon(\sigma \tau \omega \nu$, la posición anómala del anafórico coincide también con la inversión del superlativo (regla 39); es preciso, además, tener en cuenta que el regente va a su vez en genitivo (cf. Schwyzer, II, p. 135 s.; infra 6.2, 7.3,

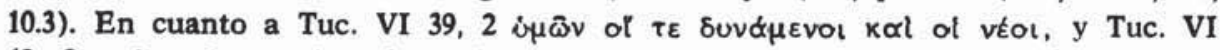

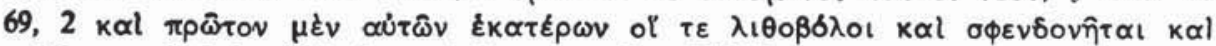

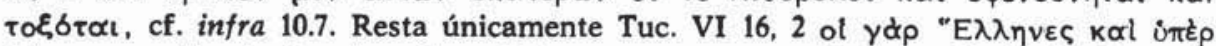

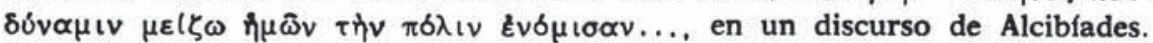

34. De las once excepciones en las que un participio sustantivado en genitivo precede al regente, en Lis. XII 36 el regente es \&petŕ (regla 6); en Lis. XII 77 , el regente es oltios (regla 2); en Lis. XXIV 14, el regente es Épyov (regla 9). Por otro lado, la inversión del participio coincide con las excepciones a otras reglas: en And. I 56 y Lis. III 16 coincide con la inversión de oủ $\varepsilon v$ y la aparición de varias negaciones más (regla 37); en And. I 60 coincide con la inversión de un superlativo (regla 39); en And. I 35 coincide con la inversión del regente $\pi 0 \lambda \lambda_{0}$ (

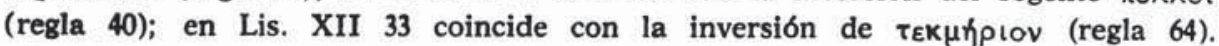


Finalmente, en Tuc. VI 1, 1 y And. I 49 el genitivo depende de un nombre neutro, y éstos, como trataremos de hacer ver, ofrecen ciertas peculiaridades (cf. 10.1).

5.3 Un numeroso grupo de palabras, por el contrario, manifiestan una clara tendencia a ocupar el primer lugar en un sintagma de nombre-genitivo ${ }^{17}$. Preceden al genitivoque de ellas depende las siguientes:

\section{Regentes

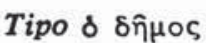 \\ Regente-regido os 'A}

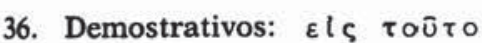

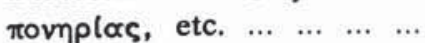

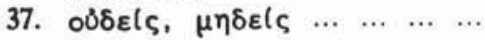

11

38. Pronombres relativos: ठ̌s, $\delta \pi \delta \sigma o s$, etc. $\ldots \ldots \ldots \ldots \ldots$

39. Comparativos y superlati$\begin{array}{llllllllll}\operatorname{vos} & \ldots & \ldots & \ldots & \ldots & \ldots & \ldots & \ldots & \ldots\end{array}$

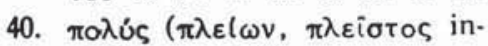
cluidos en 39$)$..............

41. Tis $\ldots \ldots$

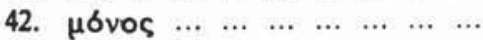

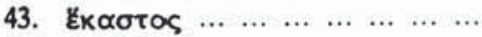

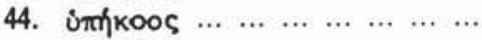

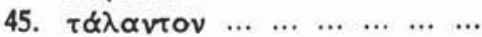

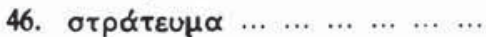

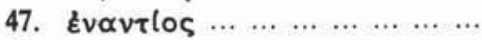

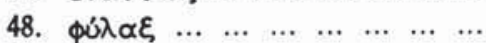

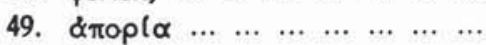

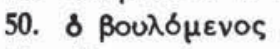

51. $\varepsilon$ l's

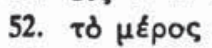

53. $\sigma \omega \tau \eta p l \alpha$

55. uloc

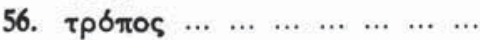

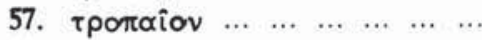

58. of xpyorol $\ldots \ldots \ldots \ldots \ldots$

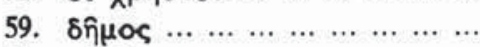

60. of \&pxovtes $\ldots \ldots \ldots \ldots$

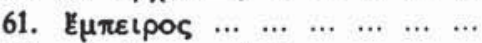

62. of $\mu \dot{\varepsilon} v \ldots$ of $\delta \varepsilon \ldots \ldots \ldots \ldots$

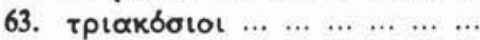

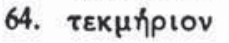

17 Muchos de los ejemplos incluidos en esta lista coinciden con la categoría que Dover, op. cit., p. 20 ss., clasifica bajo el epigrafe «preferential words». 
Un grupo numeroso de excepciones a las reglas anteriores obedece a las mismas causas expuestas en los parágrafos precedentes:

36. En tres ejemplos el demostrativo está precedido de un relativo por él regido (regla 67); en uno está precedido por otro demostrativo (regla 65). En dos ejemplos (And. I 56 y 60) la inversión del demostrativo coincide con la posición anómala de un superlativo (regla 39). La excepción que resta es Tuc. VI 18, 7

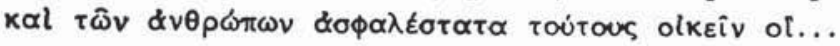

37. De las 18 excepciones, en 9 oúbદls está precedido de una o varias negaciones, circunstancia que permite asegurar que oủ $\varepsilon l s$ tiene en estos ejemplos

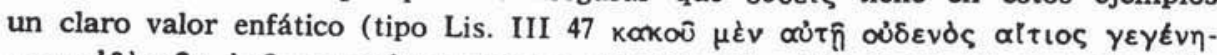

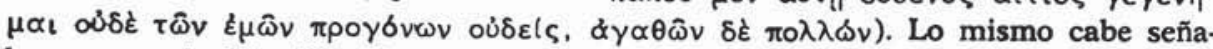

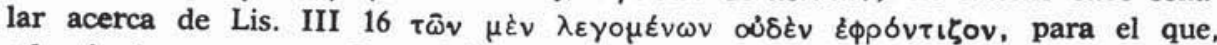
además, hay que notar la posición anómala del participio (regla 34). De las restantes excepciones, en 5 oủঠels está precedido por un demostrativo regido (regla 65), y en 2 por un relativo en genitivo (regla 67). El único ejemplo que queda es

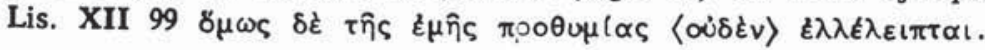

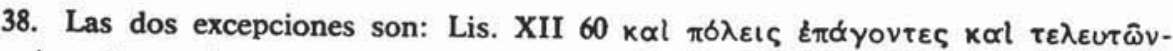

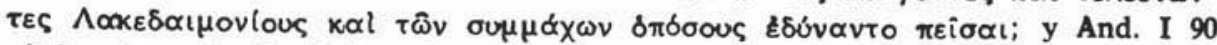

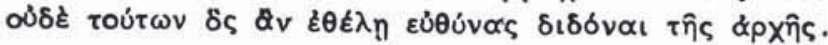

39. De las 39 excepciones, en 9 el comparativo o superlativo sigue a un demos-

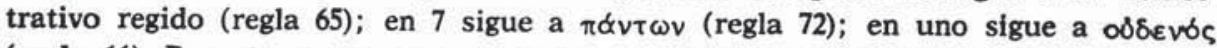
(regla 66). Por otra parte, tres excepciones aparecen en una secuencia típica, cuyo

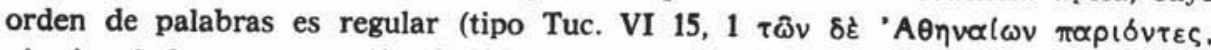

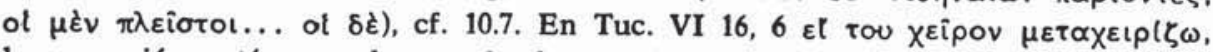

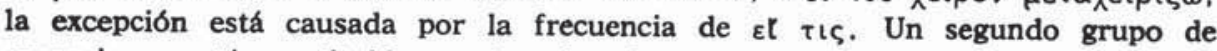
excepciones está constituido por los ejemplos en los que coincide la posición irregular del comparativo o superlativo con la inversión del orden habitual de otras palabras: en And. I 56 y 60 coincide con la inversión de un demostrativo regente (regla 36); en And. I 38, con la anteposición del anafórico (regla 33). Finalmente, en algunos otros ejemplos son evidentes causas de tipo contextual, como en

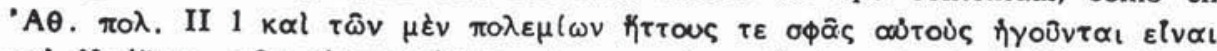

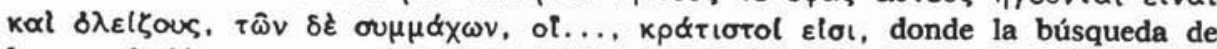
la correlación y el contraste puede justificar el orden inverso. Igualmente, en

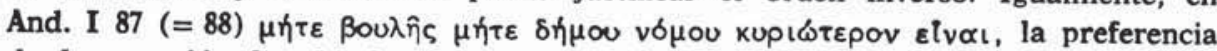
de la negación ha desplazado al genitivo comparativo de su posición habitual.

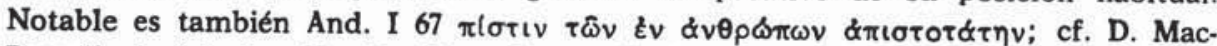

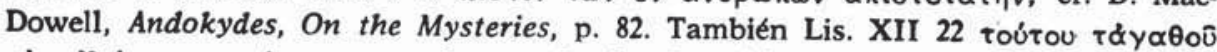

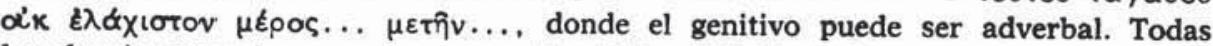
las demás excepciones pertenecen a Tucídides (VI 16,$6 ; 37,1 ; 68,2 ; 89,5 ; 90,3$; 91, 4).

40. De las seis excepciones merece mención especial Tuc. VI $105,1 \mathrm{k} \alpha$ ใิทิ $\gamma \eta \hat{s} \tau \eta \dot{v} \pi 0 \lambda \lambda \eta \dot{v} \varepsilon \delta \hat{\epsilon} \omega \sigma \alpha \nu$, construcción habitual en Tucídides, que, en general, se interpreta como fósil de un antiguo genitivo partitivo adverbal (cf. Schwyzer, II, p. 102). Hay que señalar que las restantes excepciones (And. I 35; Tuc. VI 59, 2; 
$100,2 ; 101,5 ; 103,1)$ aparecen en contextos semejantes al anterior y, por tanto, el orden de palabras puede constituir un resto de un arcaísmo sintáctico.

41. De las 19 excepciones, en dos $\tau$ ı५ sigue a un demostrativo regido (regla 65);

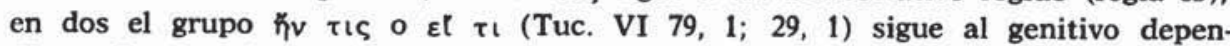

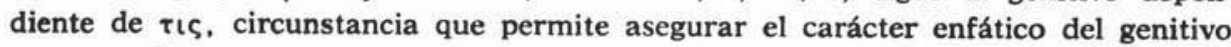
correspondiente, porque, como es sabido, las conjunciones suelen comenzar la oración; en un ejemplo más, тıৎ sigue al relativo en genitivo (regla 67); en tres ejemplos (Lis. XII 30 , And. I 78 , Tuc. VI 60,2 ) el genitivo $\tau$ เvós sigue al genitivo que depende de él, y el orden de palabras en estos casos presenta ciertos caracteres especiales (cf. infra 6.2, 7.3, 10.3). En And. I 82 la inversión del orden habitual de $\tau$ ı nal (regla 33). Conviene finalmente señalar que un grupo numeroso de excepciones está constituido por los ejemplos en los que el genitivo de un étnico precede a

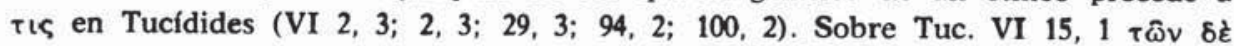

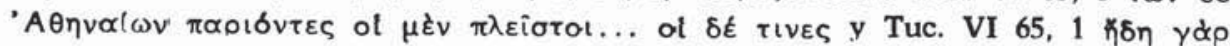

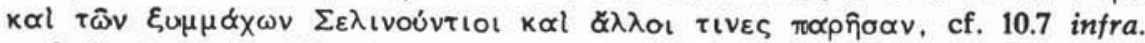

Anómala es también la posición del interrogativo $\tau$ l tras un genitivo en And. I 39 (sobre la posposición de los interrogativos, cf. G. Thomson, CQ 33, 1939, p. 147 ss.).

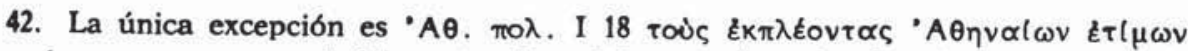
Qิv $\mu \delta$ vous, aunque probablemente el genitivo no depende de $\mu \delta$ vous, que serfa

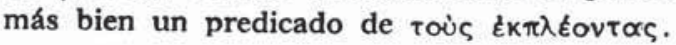

43. De las tres excepciones, en una ěk đoros va detrás del relativo en genitivo (regla 67); en And. I 57 y 104 la inversión de Ěkaotos coincide con la posición irregular del genitivo del pronombre personal.

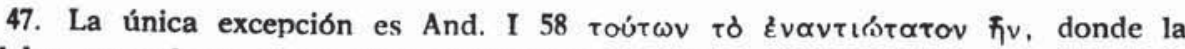
palabra precedente es un demostrativo en genitivo (regla 65).

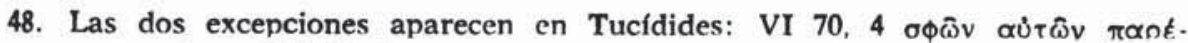

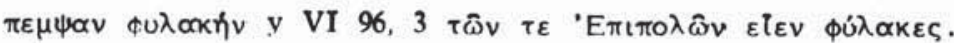

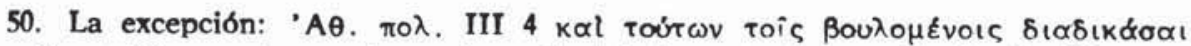

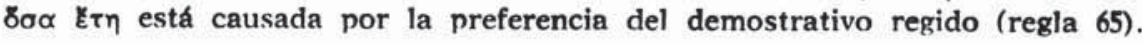

51. De las tres excepciones, dos están causadas por la preferencia del relativo

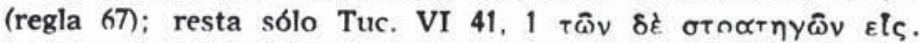

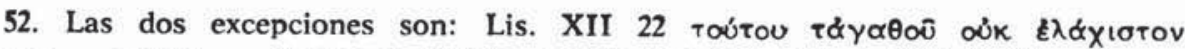

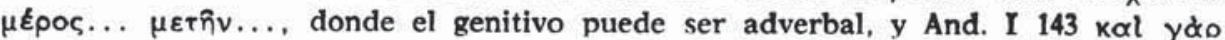

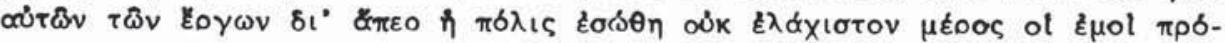

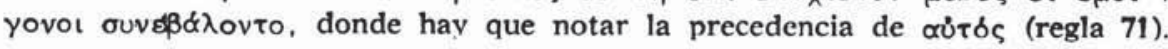

53. Los dos ejemplos en los que $\sigma \omega \tau \eta$ ol $\alpha$ no precede al nombre regido (Tuc. VI 78, 3; Lis. XII 31) son resultado del carácter preferente de los reflexivos (regla 69). 
55. El único ejemplo en el que utós sigue a su régimen es Tuc. VI 54, $6 \mathrm{k} \alpha \mathrm{l}$

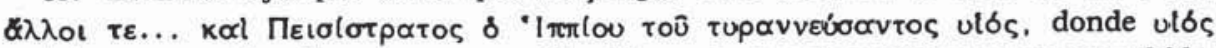
podrla ser considerado como una explicación posterior al genitivo; como es sabido, el genitivo con o sin artículo en un nombre propio indica lo mismo (cf. 9.5).

56. La única excepción en la que $\tau \rho \delta$ toৎ sigue a su régimen es Lis. XII 98, donde la inversión obedece a la aparición de un demostrativo en genitivo (regla 65).

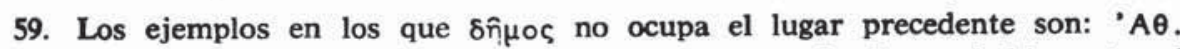

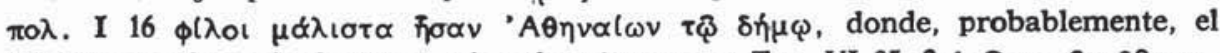

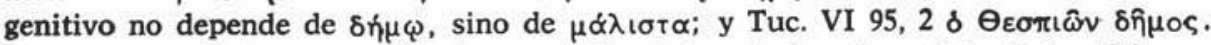
Para la repetición o ausencia de repetición del artículo, véase infra $\S 6$ y 9.4 .

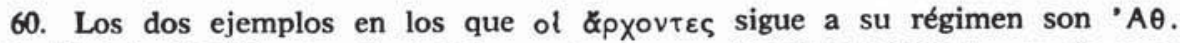

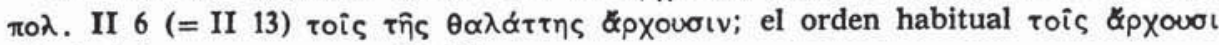
$\tau \hat{\text { Tิ }} \theta \alpha \lambda \alpha \tau \tau \eta \bar{s}$ aparece en II 418.

61. La inversión del orden habitual (Tuc. VI 36, 3) está causada por la precedencia de $\pi 0 \lambda \lambda \omega \widehat{\nu}$ (regla 68).

62. Si bien una pura consideración numérica de los datos haría pensar que la distribución de of $\mu \dot{\varepsilon} v$... of $\delta \dot{\varepsilon} \ldots$ con un genitivo puede preceder o seguir al nombre regido, criterios de diferente tipo permiten afirmar que en estos ejemplos el orden de palabras habitual era la precedencia del pronombre; como es sabido, éste es uno de los casos en los que el artículo en ático conserva su antiguo valor de pronombre; la conservación del antiguo valor pronominal, por otra parte, está asociada a determinadas secuencias en principio de frase, sobre todo (cf. Schwyzer, II, p. 21). Por otro lado, todas las excepciones pertenecen a un tipo único y regular, representado, por ejemplo, por Tuc. VI $90,3 \tau \hat{\tau} \nu \pi \delta \hat{\lambda} \varepsilon \omega v$

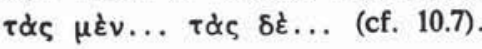

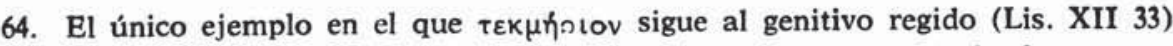
coincide con la posición irregular del genitivo del participio sustantivado.

5.4 Un cuarto grupo de ejemplos que manifiestan un orden regular está constituido por las palabras que en genitivo suelen preceder al regente. Son éstas las siguientes:

18 En la 'A $\theta \eta v \alpha l \omega \nu \pi 0 \lambda i \tau \varepsilon l \alpha$ aparecen solamente con - $\sigma \sigma-\& \sigma \sigma \alpha$ (II 17) y $\theta \propto \lambda \propto \propto \sigma \sigma o k \rho \alpha \tau o p \varepsilon s$ (II 2, II 14), frente a - $\tau \tau$ - en todos los demás casos. La forma anómala $\theta \alpha \lambda \propto \sigma \sigma o k \rho \alpha \tau o p \varepsilon \varsigma$ probablemente se justifica por tratarse de un término tomado en préstamo de Heródoto (III 122, V 83); cf. H. Frisch, The Constitution of the Athenians, Copenhague 1942, p. 243 (para la alternancia $-\sigma \sigma-/-\tau \tau$ - en ático, cf. recientemente E. Crespo, CFC 16, 1979, p. 109 ss., con bibliogr.). Es posible que estas excepciones tengan cierta relación con los ejemplos seffalados, aunque ésta se nos escapa. 


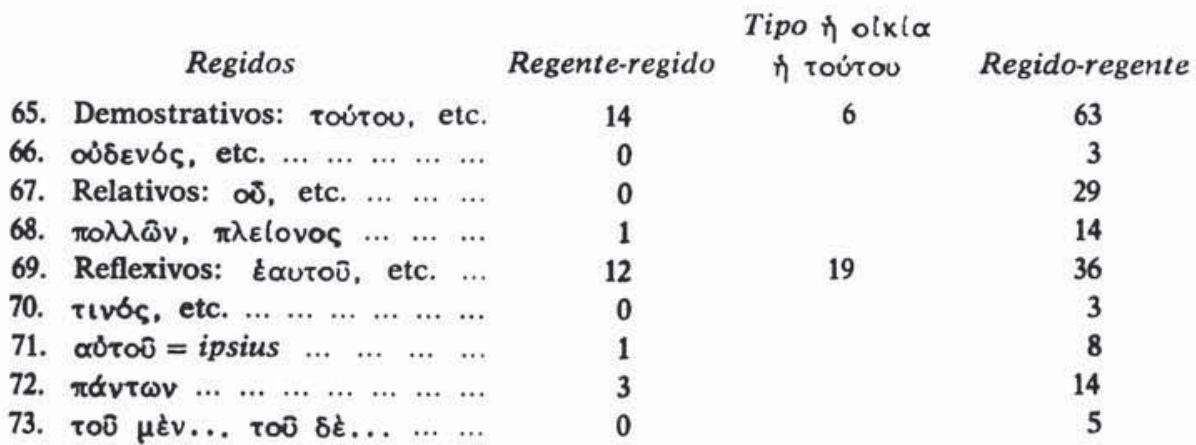

Como en las categorías anteriores, un numeroso grupo de excepciones puede hallar una justificación:

65. De las 14 excepciones, dos obedecen a la prioridad del relativo que rige al demostrativo (regla 38); en tres el demostrativo sigue a $\tau$ เ५ (regla 41); en dos sigue a un comparativo o superlativo (regla 39); en dos sigue a évavilos (regla 47); en una sigue a $\pi 0 \lambda \lambda$ ol (regla 40) y en una sigue a $\mu \eta \delta \varepsilon v \alpha$ (regla 37).

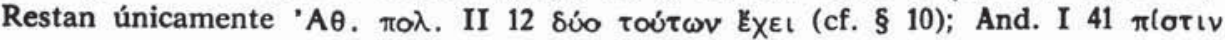

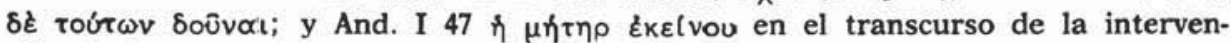
ción de los testigos. Este ejemplo excepcional es aún más notable porque existen otros muchos semejantes que son contrarios (cf. infra 6.2).

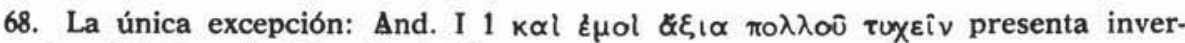
sión de $\pi \circ \lambda \lambda \circ 0 \hat{~ y ~ d e ~ « \xi ı ~ ı ~(r e g l a ~ 2) . ~}$

69. De las 12 excepciones, en tres el reflexivo sigue a un comparativo (regla 39);

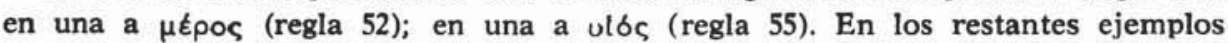
de inversión (Lis. XII 96; III 30; XXIV 2; Ant. VI 12; And. I 127, 127, 132), el reflexivo depende de un acusativo que es predicado de $\varepsilon l \mu(\mathrm{y}$, por tanto, carece de artículo.

71. La única excepción aparece tras un relativo regente (regla 38).

72. En las tres excepciones en las que $\pi \dot{\alpha} v \tau \omega v$ sigue a la palabra de la que depende (Lis. XII 26; III 39; Ant. VI 48), $\pi \dot{\alpha} v \tau \omega \nu$ está precedido por un superlativo (regla 39).

En conclusión, pues, los datos precedentes muestran que existe una regularidad en la ordenación de los elementos que componen el sintagma de genitivo adnominal-regente o viceversa. Esta regularidad es aún mayor si se tiene en cuenta que un grupo numeroso de excepciones es producto de la coincidencia en el mismo contexto de dos palabras con una tendencia semejante a aparecer, bien sea en segundo lugar, bien sea en el primero. Incluso dentro de estos ejemplos, en 
aquellos en los que los datos son numerosos se puede observar que también existe un orden habitual y que las excepciones se producen siempre en el mismo sentido; es decir, existe, al menos donde los datos permiten observar un número suficiente de ejemplos, una jerarquía de preferencia en la observación de cada una de las reglas léxicas de las listas anteriores, de suerte que, por ejemplo, se puede llegar a la afirmación de que la regla $x$ tiene carácter preferente sobre la regla $y$. Esta situación ideal, en cambio, no se puede establecer para otras reglas, bien por la ausencia de ejemplos numerosos entre los datos recogidos, bien porque las excepciones afectan a las dos reglas en cuestión.

Por otro lado, en otras excepciones el orden anómalo de los elementos coincide con otros hechos que hacen ver con claridad su carácter excepcional: el orden irregular del otro elemento que compone el sintagma, o el orden anómalo de los otros elementos que componen la frase (interrogativos, conjunciones, etc.). El carácter acumulativo de estas desviaciones muestra también que el orden anómalo ha sido buscado deliberadamente, y no obedece al azar o a la deficiente formulación de una regla de las anteriores.

6. Es preciso ahora examinar el orden de palabras del tipo í olkla

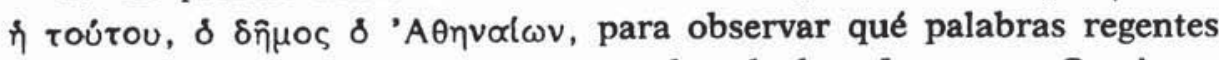
y regidas son susceptibles de este orden de los elementos. Gracias a este examen, será posible formular nuevas reglas léxicas que determinan el orden de palabras.

En los datos extraídos de las obras analizadas hay un total de 83 ejemplos de este tipo de orden de palabras. Los genitivos regidos pertenecen en su gran mayoría a unas clases de palabras bien determinadas: reflexivo en singular (19 ejemplos), nombre propio de persona (36 ejemplos), étnico (15 ejemplos) y demostrativo (16 ejemplos). Los restantes nombres regidos son:

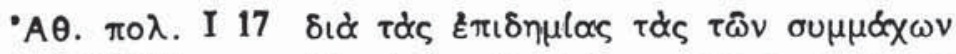

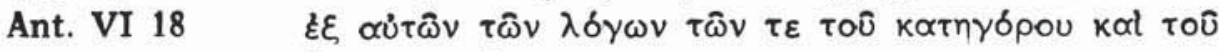
\&ँokpเvoukvou

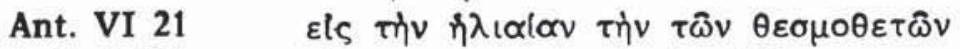

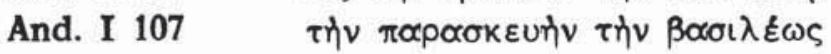

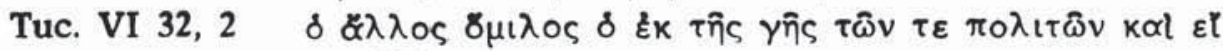
TIS $\& \lambda \lambda$ OS

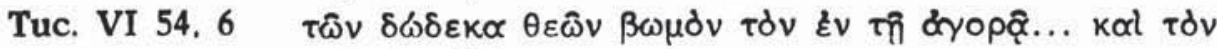
$\tau \circ \sigma^{\prime} \mathrm{A} \pi \delta \lambda \lambda \omega \nu \circ \boldsymbol{S}^{\prime}$

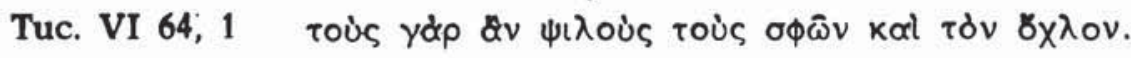


En cuanto a los nombres regentes, los siguientes aparecen en dos

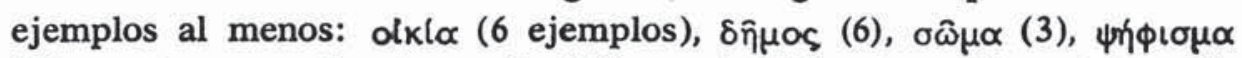

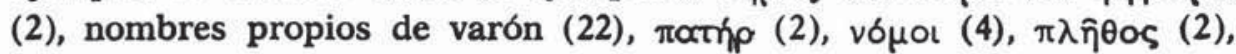
$\pi \alpha \tau p l s$ (2) ${ }^{19}$.

6.1 Una pura consideración numérica de los datos muestra que cuando el regido es un pronombre demostrativo o reflexivo el orden

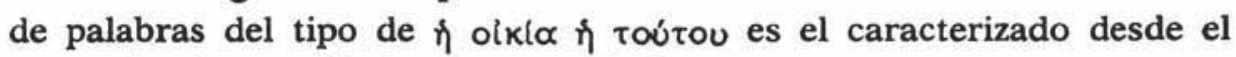

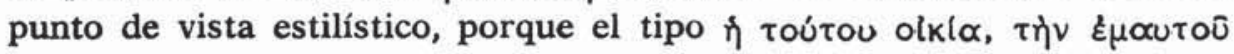
olklov es mucho más frecuente (reglas 65 y 69). Esto quiere decir que

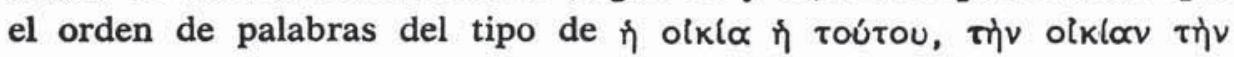

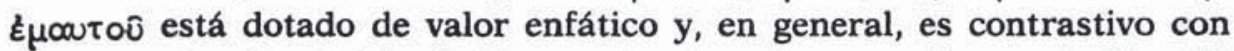
respecto al orden habitual. Un par de ejemplos procedentes de Lis. III bastarán para mostrarlo. El cliente de Lisias se defiende contra la acusación presentada por Simón bajo la denuncia de malos tratos; la causa de la diferencia entre ambos es un asunto un tanto indigno para el cliente de Lisias, un ciudadano respetable y ya anciano, porque la querella es consecuencia del amor de ambos por un joven. Por esta razón, el discurso de defensa debe comenzar con una disculpa por parte del cliente de Lisias, haciendo constar que es por supuesto inadecuado para una persona de su edad ( $\tau \dot{\eta} \nu \hat{\eta} \lambda \iota k\langle\alpha \nu \tau \eta \dot{\eta} \varepsilon \mu \alpha u \tau o \hat{)}$ manifestar tales inclinaciones. El énfasis del reflexivo parece evidente. En III 28 se defiende contra la acusación de haber ido a casa de Simón

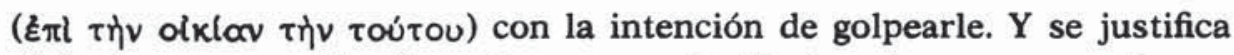
diciendo que no sólo él no fue a casa de Simón, sino que, por el contrario, fue éste quien asaltó su casa en una ocasión precedente y entró hasta la habitación de las mujeres; además, no es verosímil que él se hubiera atrevido a ir solo, si es que en realidad tenía esas intenciones; finalmente, si en un tiempo anterior él había emigrado de Atenas para evitar la vecindad de Simón y se había llevado consigo al joven, con quien seguía viviendo, ¿cómo ahora iba a haber ido a su propia casa? En fin, toda la sección 28-34 del discurso está destinada a probar la inverosimilitud de este acto del que le acusa Simón. En conclusión,

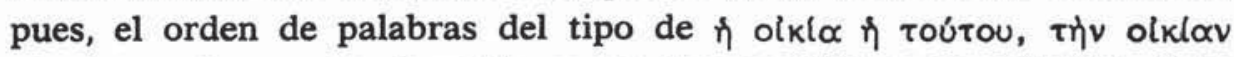
$\tau \eta \dot{v} v \varepsilon \mu \alpha u \tau(0)$, cuando el regido es un demostrativo o un reflexivo, tiene función enfática.

Sin embargo, cuando el genitivo regido es un nombre propio o un étnico, no siempre es posible atribuir a este orden de palabras (tipo

19 Para algunos otros ejemplos que merecen mencion, cf. 9.3-5. 


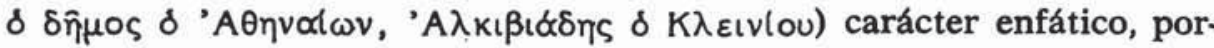
que, al menos en determinados ejemplos, las listas precedentes (§ 5) muestran que no existe otra posibilidad en el orden de palabras, al contrario de lo que sucede cuando el regido es un demostrativo o un reflexivo. En efecto, según se ha visto, sólo es regular el orden 'A $A$ KL-

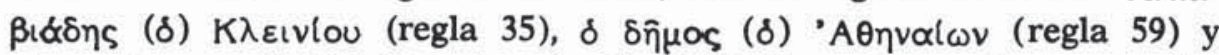

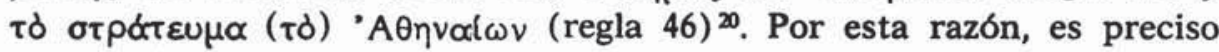

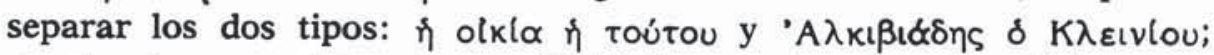
en el primero existen dos posibilidades en el orden de palabras; en el segundo, en cambio, sólo existe un único orden de los elementos.

Una segunda diferencia importante entre ambos es que el nombre

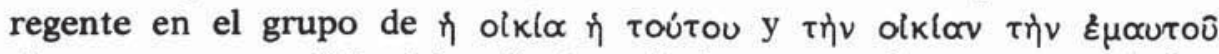
siempre va precedido del artículo, mientras que, al menos en el tipo

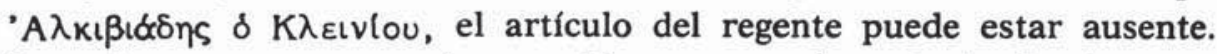
Por estas razones es preciso considerar separadamente los hechos que se refieren a cada uno de ambos.

6.2 Como se ha visto en algunos de los ejemplos precedentes, la inversión con repetición del artículo del nombre regente es producto

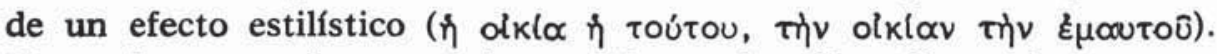
Sin embargo, en las excepciones a las reglas 65 y 69 se observa que existen también ejemplos de inversión sin repetición del artículo. En apariencia, pues, existen en la prosa literaria ática dos sintagmas ligeramente diferentes para la expresión de una misma función: la inversión simple, es decir, las excepciones a las reglas 65 y 69 en la lista precedente, y la inversión con repetición del artículo del regente. No obstante, las diferencias entre ambos son notables: el tipo iो olkl $\alpha$ in

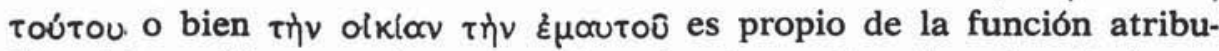
tiva del genitivo posesivo; por el contrario, en los ejemplos de inversión simple el pronombre regido nunca es posesivo (los regentes son

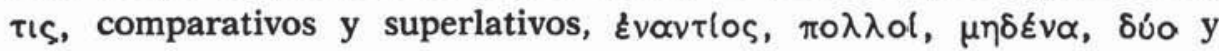
$\pi(\sigma \tau i v)$ y, si lo es, depende de un predicado sin artículo. Así, pues,

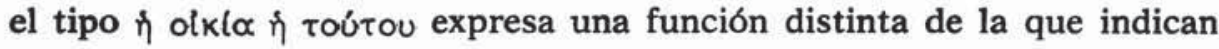
los ejemplos de inversión sin repetición del artículo.

Por otro lado, en determinadas condiciones se conservan en ático dos sintagmas ligeramente diferentes para expresar la misma función: en la designación oficial de los nombres propios de varón, donde alter-

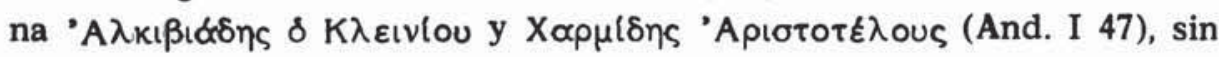

20 Lo mismo sucede en los ejemplos mencionados en 9.3-5. 
diferenciar función atributiva y predicativa mediante la repetición del artículo, y en algún otro ejemplo esporádico, como And. I 47 oũtos

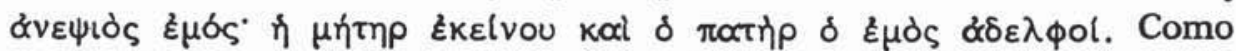
ambos aparecen en el curso de la declaración oficial de los testigos, parece razonable pensar que este hecho debe ser puesto en conexión con la frecuencia de este tipo de sintagmas en las inscripciones contemporáneas. Los numerosos ejemplos de las inscripciones y éstos de Andócides muestran que la oposición formal entre función atributiva y predicativa del genitivo es un hecho sumamente reciente (cf. Schwyzer, II, p. 26), y que en ático se conservan restos de la situación anterior,

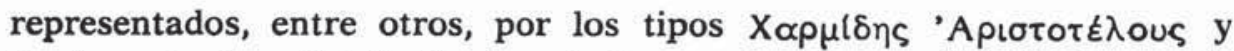

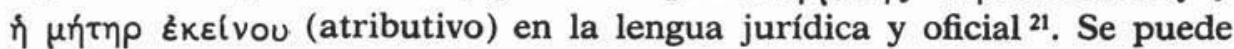

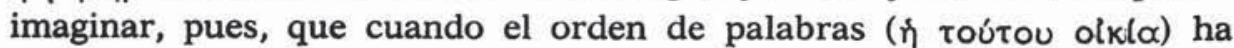
adquirido exclusivamente la función atributiva, y el orden enfático ( $\eta$

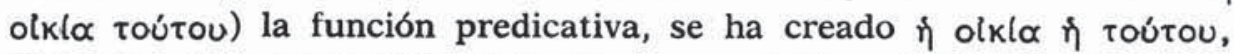
reservado para la función atributiva en posición enfática. Restos anteriores a esta diferenciación formal subsisten en la lengua oficial juridica.

Conviene, por otro lado, observar que, al menos para los genitivos de los pronombres reflexivos, el orden de palabras del tipo de $\tau \dot{\eta} \nu$

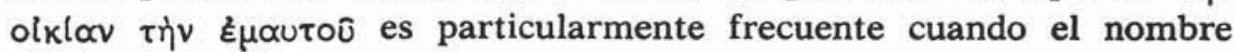
regente va en genitivo y coincide en número y género con el del re-

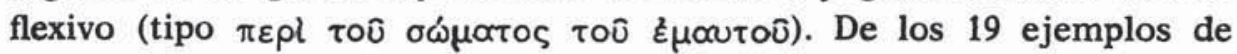
este orden de palabras con el reflexivo, en 10 aparece esta coincidencia. La necesidad de claridad y de evitar ambigüedad ha determinado en estas ocasiones el orden de palabras.

6.3 Como se ha visto, la creación de los sintagmas del tipo de

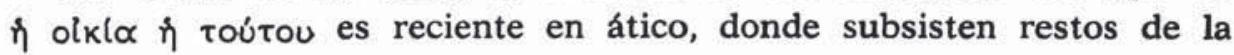
situación anterior, en la que no estaban caracterizadas formalmente función atributiva y función predicativa. Por esto es razonable pensar

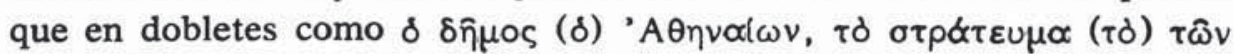

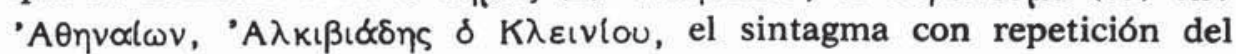

21 Como la designación oficial de los ciudadanos atenienses fue establecida por Clístenes entre los años 507 y 501 (cf. Aristóteles, Resp. Ath. 21), es posible que en el momento en que se estableció esta designación oficial no existiera aún en ático la oposición formal entre función atributiva y función predicativa mediante el artículo, y que el artículo regente en estos ejemplos se haya introducido en época posterior a la creación de tal oposición formal. No obstante, el carácter peculiar de estos ejemplos, así como su restricción a una determinada esfera oficial, impide establecer cualquier conclusión segura. 
artículo regente es una creación de época reciente que no ha sustituido por completo al más antiguo. Sin embargo, el orden de palabras pre-

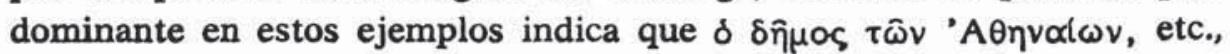

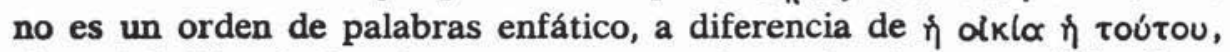
sino el habitual. Se observa, pues, que la tendencia general ha favorecido la indicación del carácter atributivo mediante la repetición del artículo del nombre regente.

En conclusión, pues, en los nombres regentes de un genitivo que admiten el orden de palabras del tipo de $\eta \hat{~}$ toútou olki $\alpha$ o bien $\eta \hat{~ o l k l \alpha}$

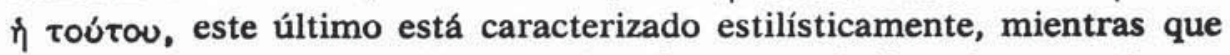
la anteposición del genitivo es el orden normal. Por el contrario, en los nombres que rigen un genitivo que sigue al regente, la repetición

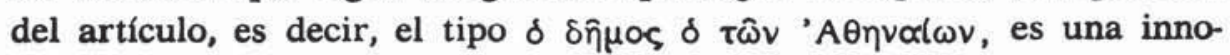
vación que resulta de la extensión progresiva de la oposición formal entre función atributiva y función predicativa.

7. Como es sabido, el genitivo posesivo o, en general, el genitivo que indica la pertenencia es susceptible de cumplir función atributiva o predicativa, mientras que el genitivo partitivo y ablativo presenta solamente el orden de palabras que indica la función predicativa (ol

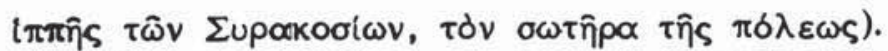

Así ocurre, en efecto, en la mayoría de los datos analizados en el presente trabajo, como se indica en el cuadro siguiente. Naturalmente, sólo están incluidos en éste los regentes que aparecen con artículo en las obras consultadas; no han sido incluidos tampoco los regentes de un genitivo del pronombre personal, porque la posición predicativa es única en tales circunstancias.

Con respecto a los nombres regentes que integran la columna I es preciso sólo señalar que se trata de nombres que rigen un genitivo posesivo o de pertenencia. Por lo demás, algunos usos que se clasifican como sincréticos (genitivo regido por $\alpha \tau i \circ \varsigma, \alpha \tau(\alpha c\llcorner\varsigma, \tau(\mu \eta \mu \alpha)$ siguen la misma norma en cuanto a la posición del genitivo con respecto al artículo del nombre regente.

El grupo mayoritario de los nombres que integran la columna II rige habitualmente un genitivo susceptible de ser considerado partitivo o ablativo. Igualmente, las palabras que componen la columna III son susceptibles de regir, en la mayoría de los casos, un genitivo que puede ser clasificado bien como posesivo, bien como partitivo o ablativo. No obstante, la discusión del grupo mayoritario de estas palabras se hará en $\S 9$. 
PALABRAS QUE RIGEN UN GENITIVO EN POSICION

\begin{tabular}{|c|c|c|}
\hline SOLO ATRIBUTIVA & SOLO PREDICATIVA & AMBAS \\
\hline 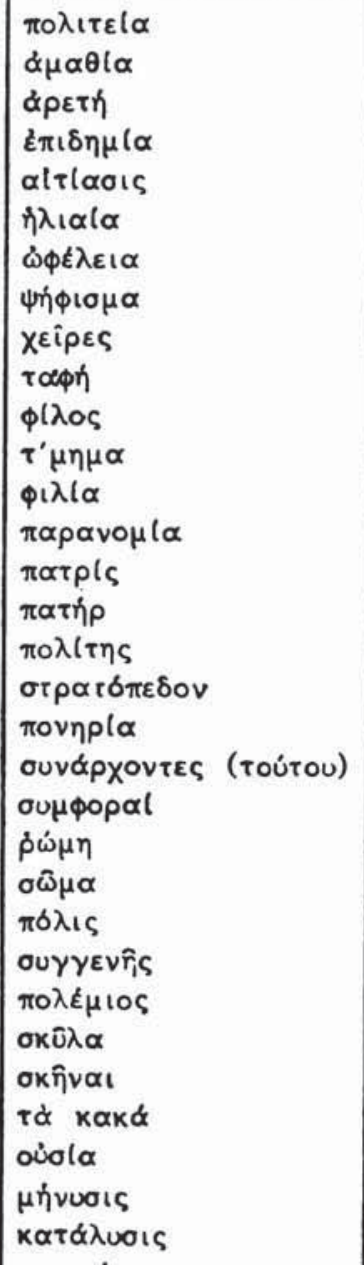 & 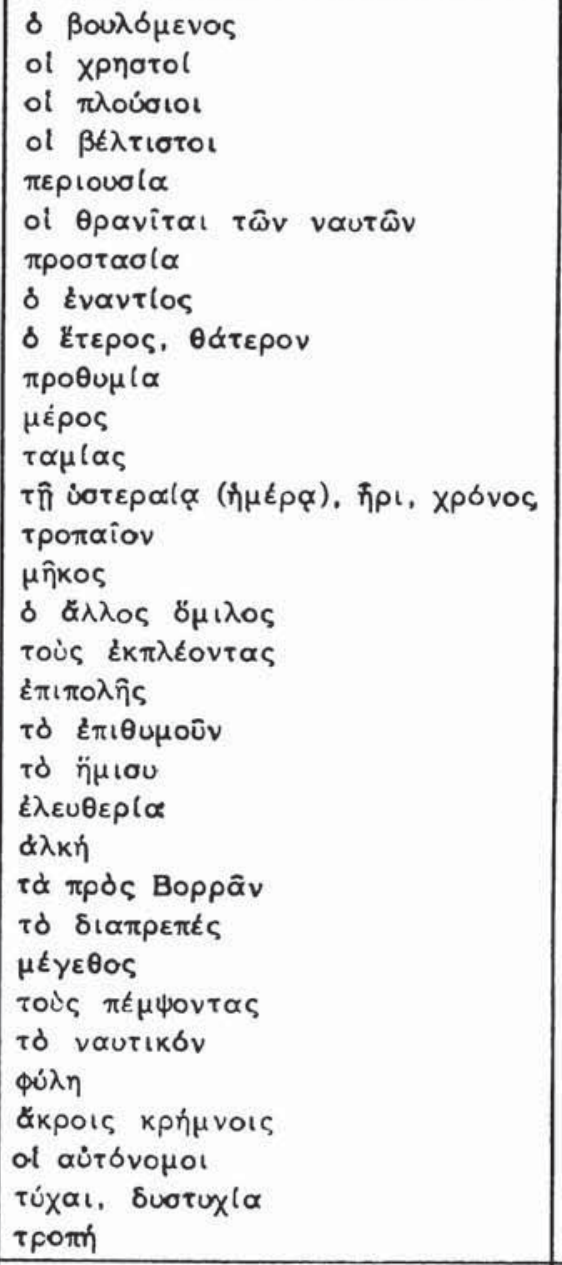 & 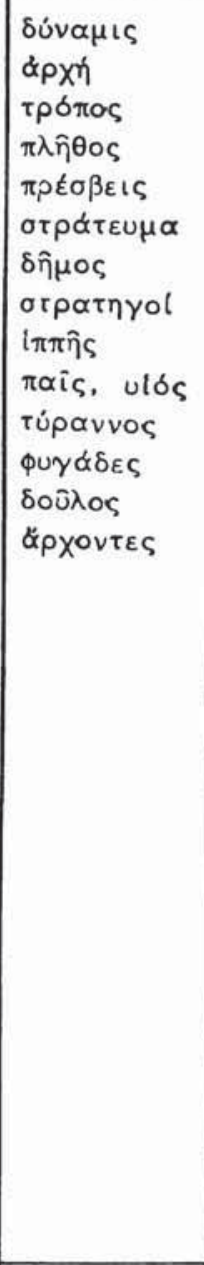 \\
\hline 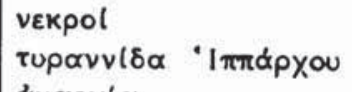 & $\begin{array}{l}\text { ктท́ } \mu \alpha \tau \alpha \\
\text { к } \alpha \tau \eta \gamma \circ \rho l \alpha\end{array}$ & 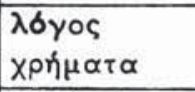 \\
\hline 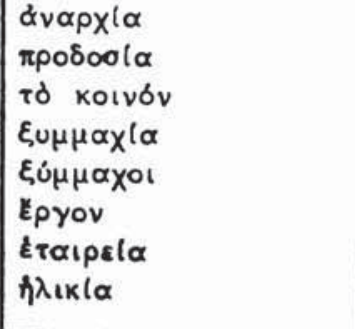 & 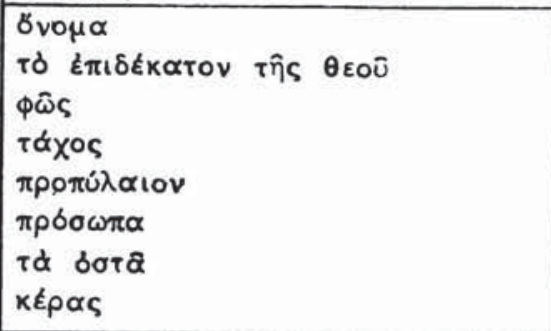 & $\begin{array}{l}\tau \delta \text { lepóv } \\
\tau \varepsilon i x \circ \varsigma\end{array}$ \\
\hline
\end{tabular}

XLIX, $1.0-9$ 


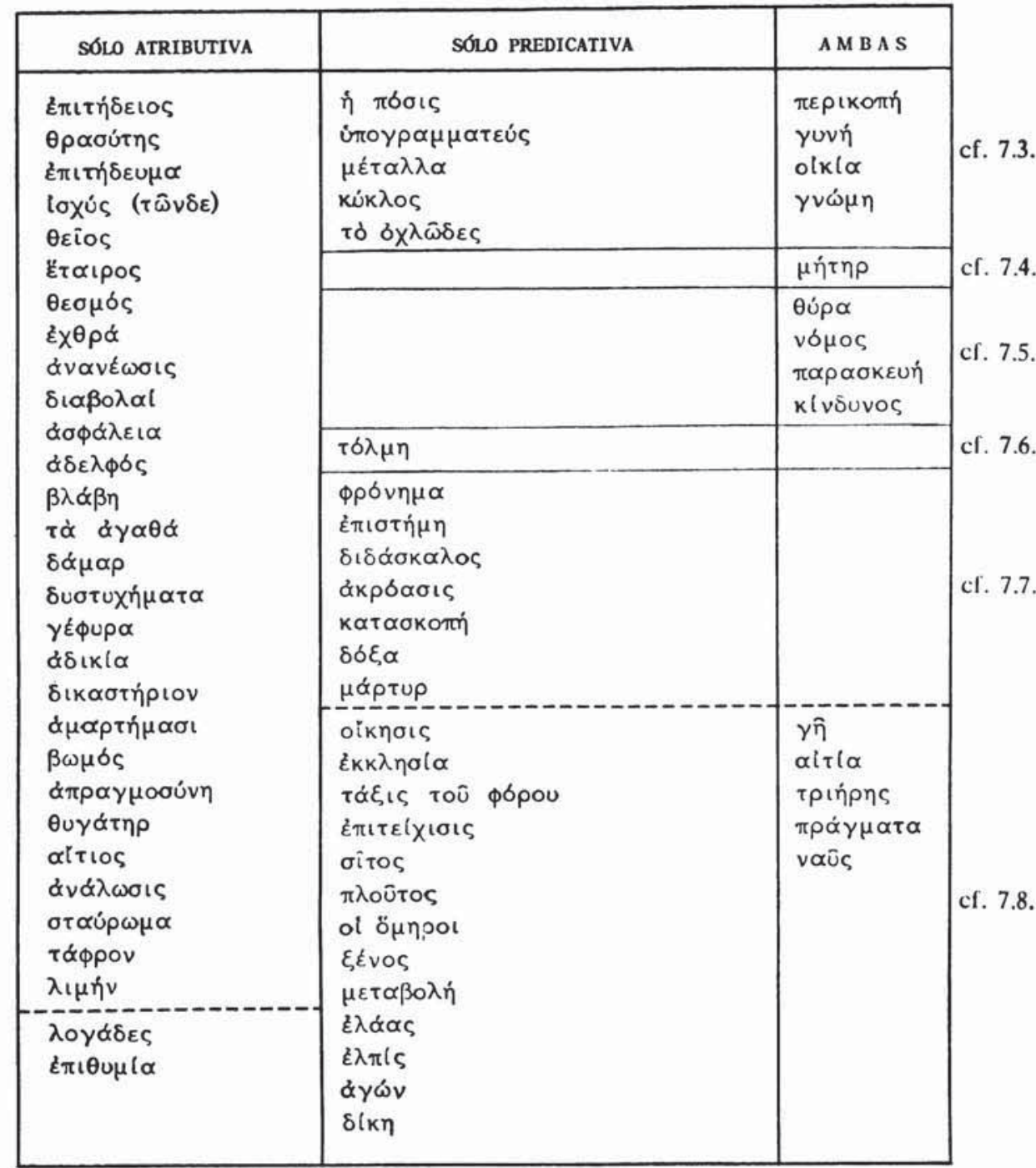

En cuanto a los grupos que en cada una de las tres columnas constituyen excepciones (señalados en el cuadro mediante líneas horizontales), conviene hacer algunas observaciones:

7.1. Cuando el regido es un participio sustantivado en genitivo, no se admite

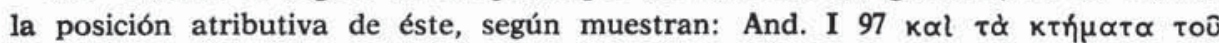

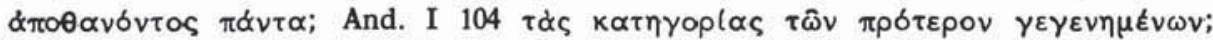

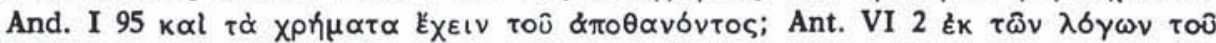

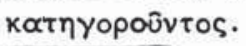

7.2. Un segundo grupo de excepciones está constituido por los nombres regentes de género neutro. Como es sabido, estos nombres presentan diversas peculia ridades sintácticas. 
7.3. Un tercer grupo de excepciones está formado por los nombres que rigen un genitivo, y el propio regente va en genitivo. Algunos ejemplos son particular-

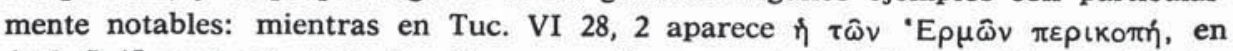

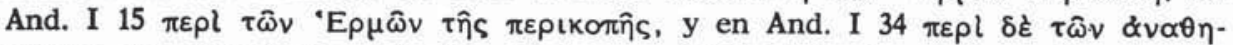

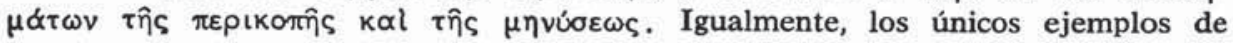
posición predicativa del genitivo regido por $\gamma u v \eta$ y olkl $\alpha$ son And. I 16 i $\gamma u v \eta$

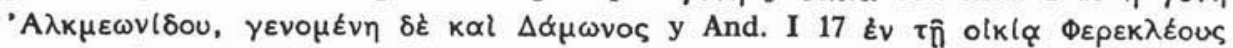

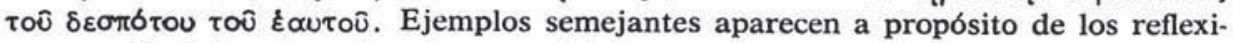
vos cuando éstos dependen de un genitivo que coincide con el reflexivo en género y número (cf. 6.2).

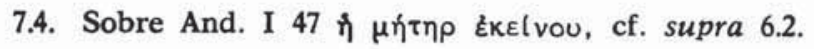

7.5. La posición predicativa del genitivo regido por ciertos nombres parece indicar una relación especial entre regente y regido, diferente del genitivo que en

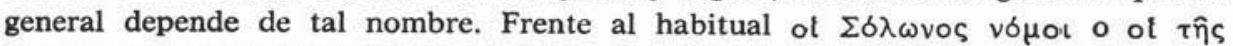

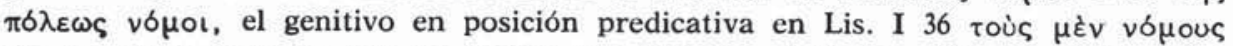

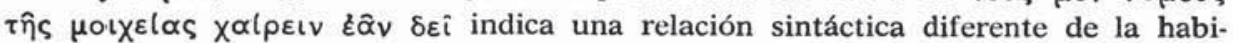
tual. Igualmente, frente a Tuc. VI 12, $2 \tau \hat{\varphi} \tau \tau \hat{\eta} \varsigma \pi \delta \delta \varepsilon \omega \varsigma$ $\kappa เ \nu \delta u ́ v \varphi$, en Tuc. VI 49, 2

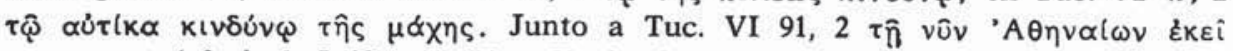

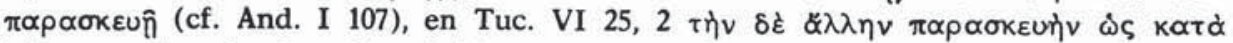

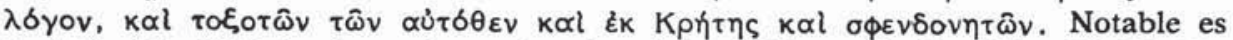
también Lis. I 24 frente a otros ejemplos de posición atributiva (Lis. III 27, 29);

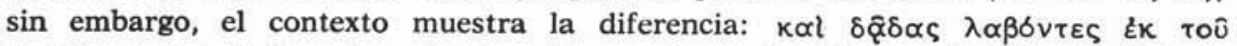

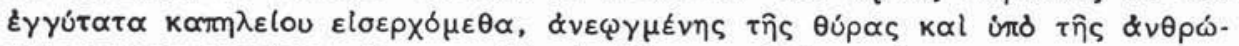

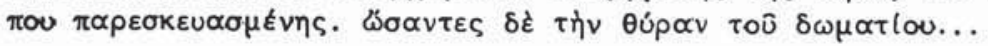

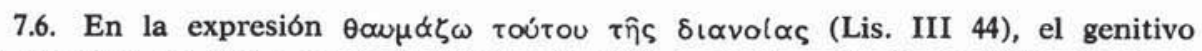
es adverbal en ático probablemente (cf. LSJ s. $u$. $\theta \alpha u \mu \alpha \zeta \omega$ ); en todo caso, en todos los ejemplos es regular la posición predicativa (cf. Lis. XII 41, etc.).

7.7. Un grupo de nombres que rige un genitivo en posición predicativa está relacionado con verbos de percepción, que, como es sabido, son susceptibles de estar acompañados por un genitivo partitivo.

7.8. Los restantes ejemplos excepcionales pertenecen en su inmensa mayoria a Tucídides; por tanto, es probable que en la lengua de Tucídides la oposición formal entre función atributiva y predicativa mediante el uso del artículo no sea completa, sino que aún queden restos de la indiferencia formal, como ocurre en la lengua jurídica y oficial contemporánea 2 . Los ejemplos que no pertenecen a

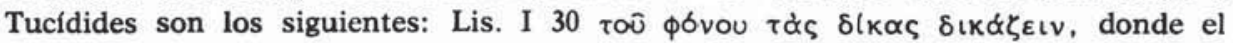

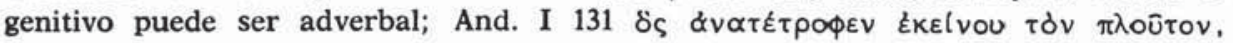

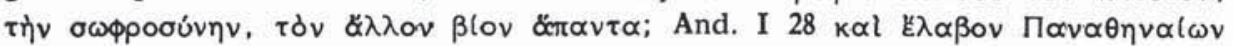

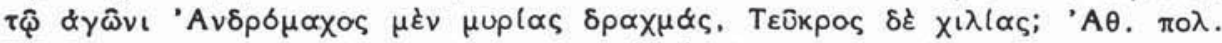

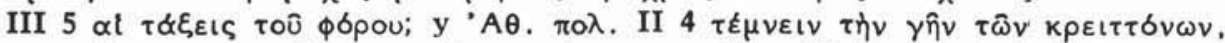

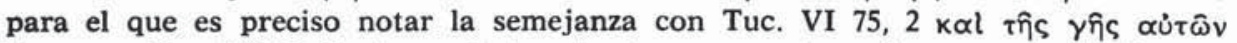

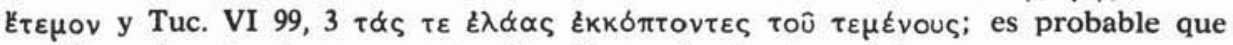
en éstos el verbo haya causado el orden anómalo de palabras.

22 Para una interpretación de los arcaísmos lingüísticos en Tucídides, cf. E. Crespo, CFC 16, 1979, p. 109 ss. y la bibliografía alli citada. 
8. Como se ha visto hasta el momento, en algunas categorías léxicas al menos (cf. § 5) es posible identificar el orden de palabras habitual. Las excepciones son poco numerosas, y en muchas de ellas se puede justificar con verosimilitud la causa del orden anómalo. Igualmente, el orden de palabras del tipo de olklo pertenece a determinadas categorías léxicas, que se caracterizan por una rección sintáctica. Además, la oposición formal mediante el artículo entre posición atributiva y predicativa es un hecho reciente en ático, donde persisten numerosos restos de la situación anterior en las inscripciones y en la propia prosa literaria (cf. 6.2 y 7.8), semejantes a los que documenta la poesía arcaica. Por otro lado, se ha visto que existe en ático una tendencia a extender la posición atributiva, en perjuicio de la predicativa (cf. 6.3).

Ahora bien, ¿bajo estas categorías léxicas y morfológicas subyace una categoría sintáctica que explique la totalidad de los ejemplos vistos? Los datos expuestos más arriba, en efecto, muestran que, en general, las palabras que sintácticamente se caracterizan por la rección de un genitivo partitivo o ablativo preceden al regido; por el contrario, las palabras que rigen un genitivo pertinentivo siguen a su régimen. En la misma dirección apuntan las observaciones que se refieren a la oposición entre función atributiva y predicativa mediante la repetición

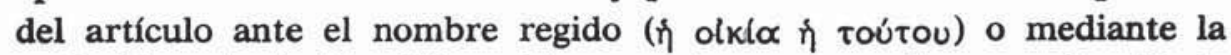
exclusión o inclusión del genitivo en el grupo que forman el artículo y el nombre regente (cf. § 7).

Todo ello permite formular la hipótesis, a expensas de ulteriores precisiones, de que el genitivo posesivo o pertinentivo precede al nombre regente, mientras que el partitivo y el ablativosiguen al regente.

9. Para verificar esta hipótesis es preciso, en primer lugar, referirse a los datos presentados en $\S \S 5-7$, que, al parecer, son contrarios a la determinación sintáctica del orden de palabras que pretendemos establecer; en segundo lugar, hay que clasificar y examinar el resto de los ejemplos que aparecen en las obras analizadas, ejemplos que en las listas de $\S 5$ no han sido tenidos en cuenta, bien porque aparecen una sola vez o dos, bien porque, aun siendo más numerosos, presentan ciertas irregularidades que merecen una discusión especial (cf. § 10).

9.1. En algunos epígrafes que componen las listas de $\S 5$ lo que determina el orden de palabras no es la función sintáctica, sino un 
hecho fonológico o morfológico. Esto es particularmente claro en las palabras que tienen carácter preferente, tanto cuando son regentes, como cuando son regidos; es decir, los relativos, los pronombres de-

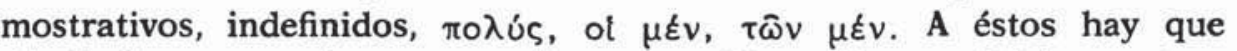
añadir los pronombres personales en genitivo y los participios sustantivados, también en genitivo. En ellos, pues, el orden de palabras no está determinado por el fundamento sintáctico que tratamos de establecer. Sin embargo, es preciso notar que en ninguna de estas categorías se viola de un modo sistemático este principio sintáctico, pues en todas ellas el genitivo puede ser partitivo, ablativo o pertinentivo, según el regente o según el genitivo que de ellas depende. A este respecto, es preciso notar que en todos los ejemplos de inversión del orden habitual que afectan a los demostrativos (cf. § 5, regla 65) la palabra regente exige un genitivo partitivo o ablativo.

9.2. En un segundo grupo de ejemplos un examen detenido permite observar que los verbos correspondientes a estos nombres o adjetivos se construyen predominante o únicamente con genitivo partitivo o abla-

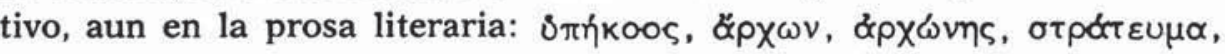

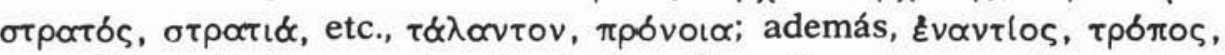

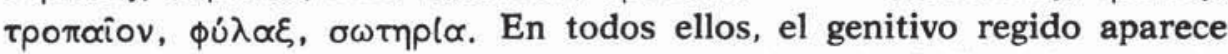
siempre o en general en posición predicativa (cf. § 7). Así, pues, la construcción de los verbos correspondientes y la posición predicativa del genitivo regido cuando el regente lleva artículo permiten interpretar como partitivos o ablativos los genitivos que dependen de tales nombres o adjetivos.

Naturalmente, a menudo es imposible trazar una frontera rígida entre unos tipos de genitivo y otros diferentes, e incluso es probable que existan variaciones entre cada autor y en cada contexto. Por supuesto, es imposible saber si en un ejemplo determinado el genitivo dependiente era concebido como posesivo o como partitivo o ablativo, a menos que existan criterios formales que lo justifiquen. A este respecto, además de la inclusión o exclusión del grupo que forman artículo y nombre regente, el criterio del orden de palabras, que se cumple en algunas categorías acerca de cuya clasificación no existe la menor duda, puede ser sumamente útil para clasificar los genitivos adnominales como posesivos o partitivos y ablativos.

9.3. Con respecto a los nombres que rigen un genitivo que aparece tanto en posición atributiva, como en posición predicativa (columna III de § 7), algunos hechos en favor de la hipótesis que tratamos de esta- 
blecer son significativos. En los datos analizados, el nombre «pxý lleva un genitivo en seis ocasiones: además de Lis. XII 96, el genitivo pre-

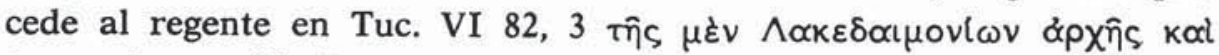

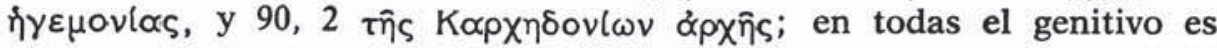
posesivo. Tres veces, por el contrario, ‘ $\alpha \times x$ precede al genitivo: And. I

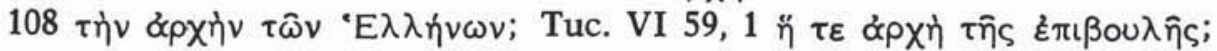

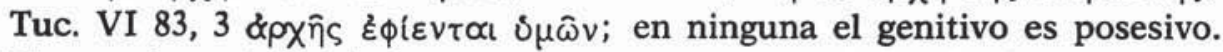
Es preciso, sin embargo, reconocer que esta situación favorable no siempre aparece con tal regularidad: $\tau$ úpavvos con un genitivo aparece tres veces en las obras analizadas; si es correcta la determinación sintáctica del orden de palabras que se ha expuesto, hay que esperar que $\tau u ́ p \alpha v v o s$ preceda al nombre regido; así ocurre, en efecto, en Tuc. VI

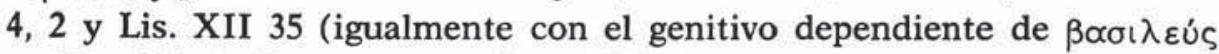

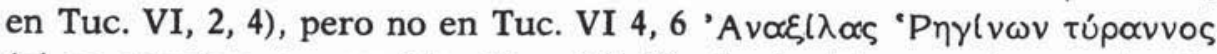

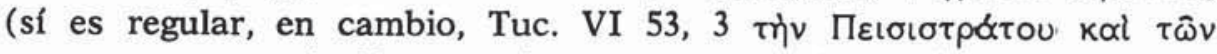
$\pi \propto\llcorner\delta \omega \nu \tau \tau u \rho \propto v v(\delta \propto)$. Algo semejante ocurre con los genitivos dependientes de $\delta 0 ́ v \propto \mu \iota \varsigma$ (partitivo postpuesto: Tuc. VI 6, 2; 46, 3; 90, 3; posesivo antepuesto: Tuc. VI 6,$2 ; 17,1 ; 31,1 ; 54,3 ; 92,5$; pero posesivo postpuesto: Tuc. VI 47,$1 ; 76,1)^{23}$.

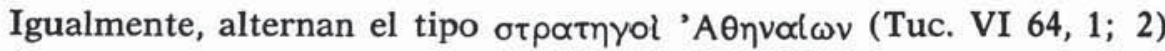
y 'A

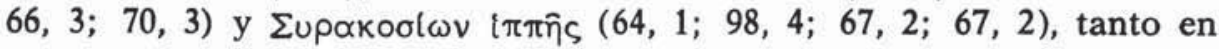
lo que se refiere al orden de palabras, como a la inclusión o exclusión del genitivo entre el artículo y el nombre regente. En ambos, el genitivo puede ser clasificado bien como posesivo, bien como partitivo, como pone de relieve, por ejemplo, Tuc. VI 66,3 of $\{\pi \pi \eta \hat{\varsigma} \varsigma \tau \hat{\omega} v \Sigma u p \alpha-$

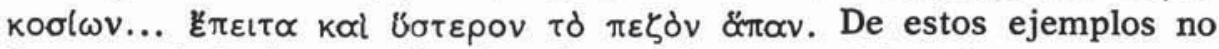
hay que deducir que el orden de palabras es arbitrario; por el contrario, el orden de palabras es el único criterio formal, además del artículo, que indica el carácter posesivo o partitivo. Idéntica alternan-

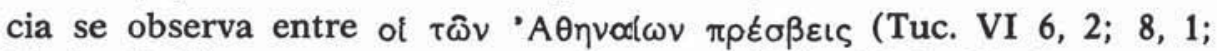

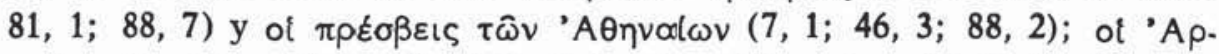

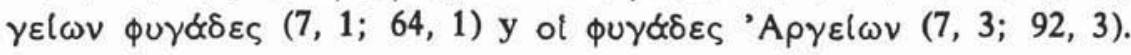

\footnotetext{
23 Los únicos ejemplos que no han sido hasta ahora mencionados de los que aparecen en la columna III de $\S 7$ son: $\tau \rho \delta \pi \circ \varsigma$, que siempre precede al genitivo

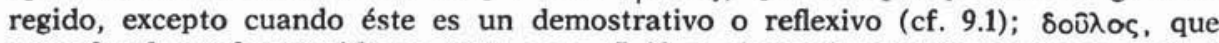
precede al nombre regido en ' $\mathrm{A} \theta$. $\pi \mathrm{o} \lambda$. I 18, y sigue al nombre regido en And. I 12; a pesar de la ausencia de más datos, el orden de palabras puede indicar que el genitivo es posesivo o que es partitivo, semejante a los que aparecen con

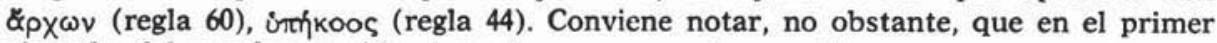
ejemplo del nombre regido depende a su vez otro genitivo.
} 
9.4. Un ejemplo semejante a los anteriores es la alternancia entre

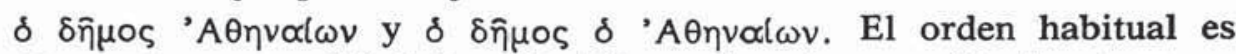
$\delta \hat{\eta} \mu \circ \varsigma^{\prime} A \theta \eta v \alpha i \omega \nu$ (cf. § 5, regla 59); en los datos analizados $\delta \delta \bar{\eta} \mu \circ \varsigma$

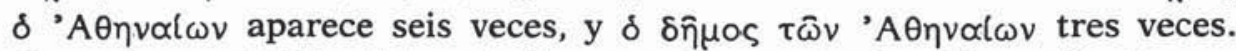
Como la repetición del artículo para marcar la función atributiva es un hecho reciente en ático (cf. 6.2), es posible suponer que $\delta \delta \hat{\eta} \mu \circ \varsigma$ $\tau \hat{\omega} v$ 'A $A \eta v \propto(\omega v$ es el tipo más antiguo, y que la repetición del artículo regente es una innovación que aún conserva el orden de palabras tradicional. El último estadio de este desarrollo estaría representado por $\delta \Theta \varepsilon \sigma \pi \iota \hat{\omega} \nu \delta \hat{\mu} \mu{ }$ (Tuc. VI 95, 2), con la adaptación al tipo habitual de los genitivos posesivos. Son susceptibles de la misma interpre-

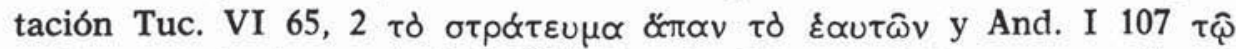

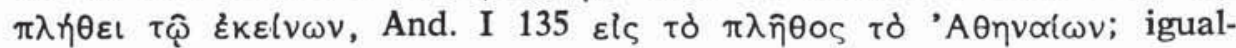
mente aquí, el punto final en el desarrollo estaría constituido por

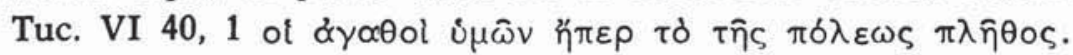

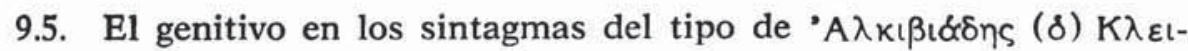
$v$ lou tiene, en determinadas ocasiones al menos, una relación estrecha con el ablativo, como demuestran los ejemplos en los que el genitivo va precedido de $\varepsilon_{\kappa}$ o đa $\pi \delta$ (cf. Schwyzer, II, p. 119). Aun así, es probable que esto sea un hecho esporádico, en cuyo caso el orden de palabras en estos ejemplos es contrario a la hipótesis que tratamos de establecer. Sin embargo, este tipo de genitivos presenta ciertos caracteres especiales ${ }^{24}$ : existe sin duda una estrecha relación entre este tipo de genitivos y el hecho de que viós preceda regularmente al nombre regido, así como la esporádica posición predicativa del nombre regido por ulós y $\pi \propto$ î́ (cf. § 7, columna III). Por otro lado, estas características no concurren en ningún otro nombre de parentesco cuando rige un genitivo. Finalmente, como es sabido, en las inscripciones (cf. Meisterhans $_{3}$, p. 206) no se repite el artículo del nombre regente, a diferencia de lo que es regular en la prosa literaria. Todos estos hechos hacen razonable pensar que este grupo de excepciones a la determinación sintáctica del orden de palabras que pretendemos establecer debe ser interpretado en términos históricos, no sintácticos. En este sentido, es posible que el orden de palabras en el tipo 'A $\lambda \kappa \iota \beta \iota \alpha \delta \eta \eta$ ( $\delta) K \lambda \varepsilon เ v$ lov

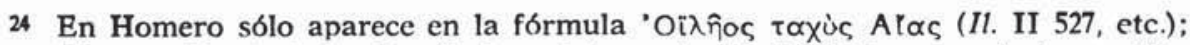

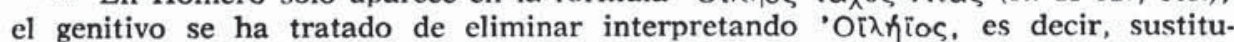
yendo el genitivo por el patronímico correspondiente (cf. P. Chantraine, Gram. hom. II, p. 61). En todo caso, su carácter único hace pensar que esta construcción con genitivo es reciente. Cf. J. M. Aitchinson, Glotta 42, 1964, p. 132 ss.; O. Masson. Glotta 43, 1965, p. 217 ss. 
sea consecuencia de la designación oficial de cada ciudadano, establecida, según nuestras noticias (Aristóteles, Resp. Athen. 21), por las reformas de Clístenes.

10. A la luz de las conclusiones obtenidas hasta el momento, hay que clasificar y examinar el orden de palabras que aparece en los restantes ejemplos que aparecen en las obras analizadas y que no han sido tenidos en cuenta hasta ahora. Como el tipo de genitivo viene determinado por el nombre regente, será suficiente clasificar las palabras que rigen genitivo e indicar si el nombre regente precede o sigue al genitivo. Quedan excluidos del siguiente cuadro los ejemplos mencionados en $\S 5$ y $\S 9$. Cada ejemplo aparece una o dos veces, cuando no se señala lo contrario.

\begin{tabular}{|c|c|c|c|}
\hline \multicolumn{2}{|c|}{ ORDEN REGENTE-REGIDO } & \multicolumn{2}{|c|}{ ORDEN RF:GIDO-RI:GENTE } \\
\hline 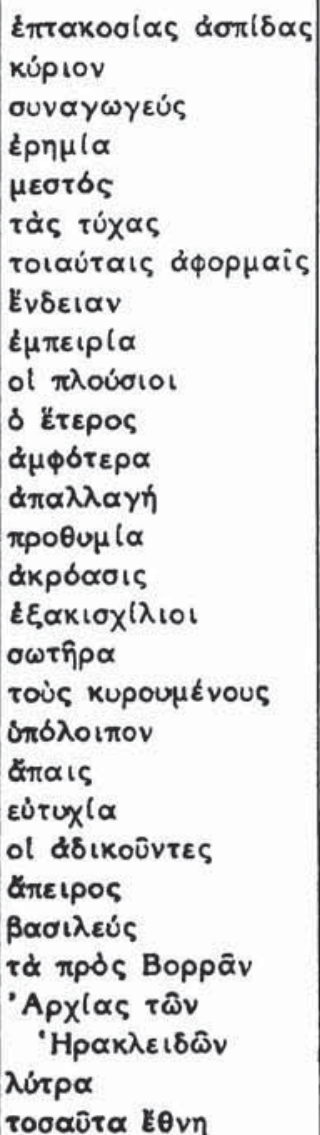 & 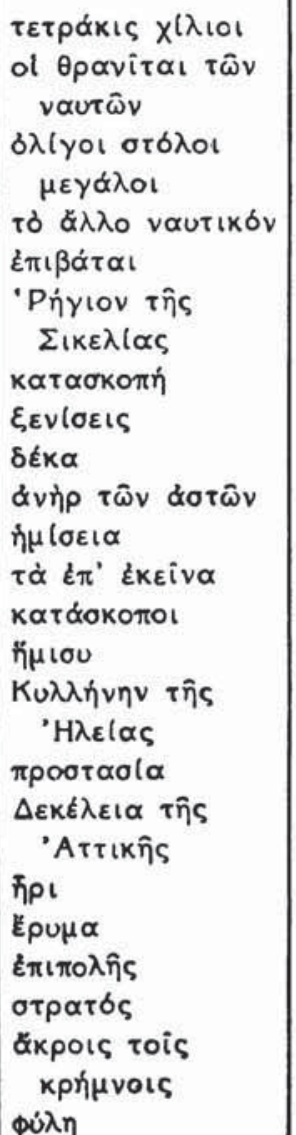 & 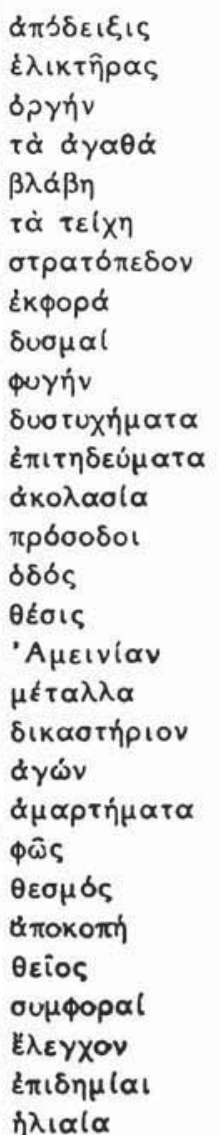 & 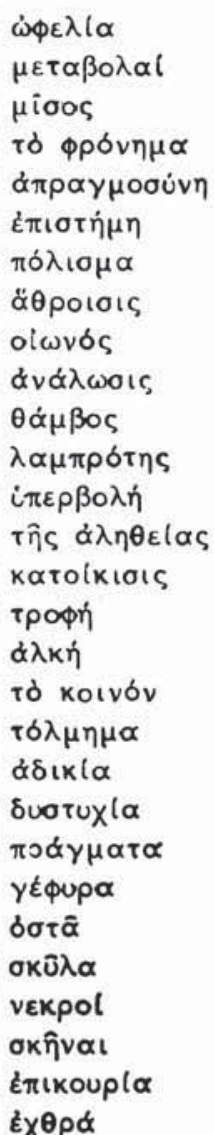 \\
\hline
\end{tabular}




\begin{tabular}{|c|c|c|c|}
\hline \multicolumn{2}{|c|}{ ORDEN REGENTE-REGIDO } & \multicolumn{2}{|c|}{ ORDEN REGIDO-REGENTE } \\
\hline 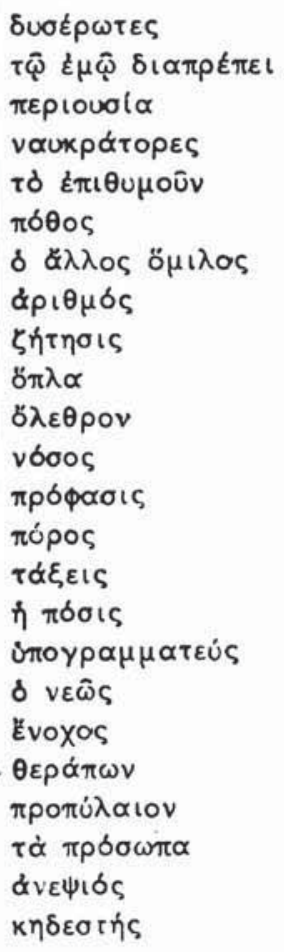 & 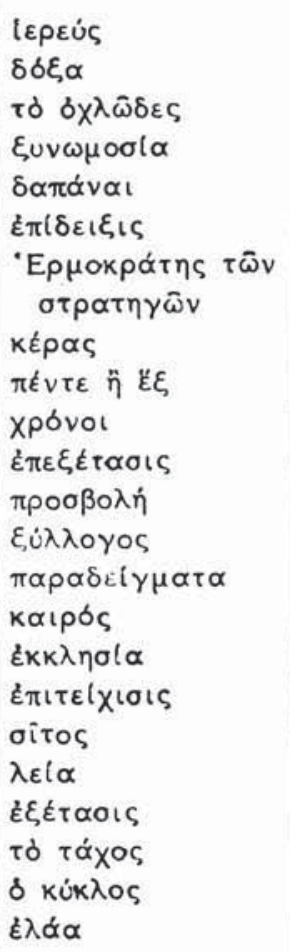 & 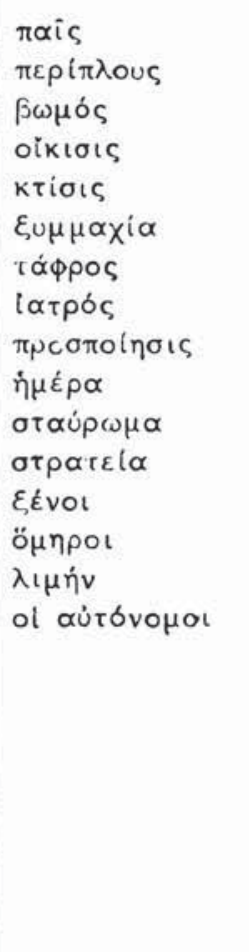 & 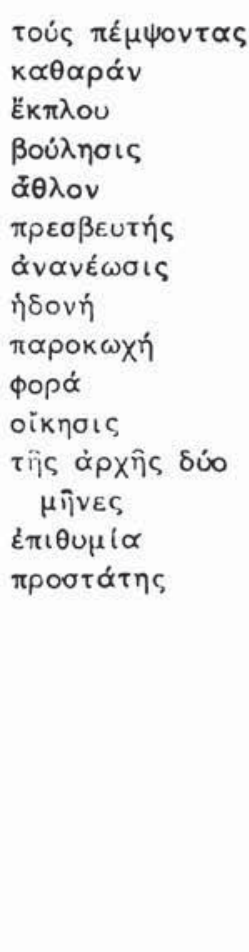 \\
\hline
\end{tabular}

\begin{tabular}{|c|c|c|c|}
\hline \multicolumn{4}{|c|}{ ORDEN RI:GENTE-REGIDO O REGGIDO-REGENTE } \\
\hline$\delta เ \delta \dot{\alpha} \sigma \kappa \alpha \lambda \circ \varsigma$ & 1.1 & 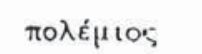 & $1-1$ \\
\hline 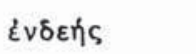 & $1-1$ & $\pi \alpha p \alpha \sigma \kappa \varepsilon \cup \dot{~}$ & 2.2 \\
\hline$\mu \varepsilon \dot{\varepsilon} \gamma \varepsilon \theta \circ$ & $4 \cdot 3$ & $\tau \alpha \mu i \alpha \varsigma$ & $2-1$ \\
\hline$\theta \dot{p} p \alpha$ & 1.2 & $x \alpha \dot{\rho} \rho เ v$ & 1.1 \\
\hline$\pi \lambda \hat{\eta} \theta$ os & $10-5$ & kivouvos & $1-1$ \\
\hline$\delta \circ 0 ิ \lambda \circ \varsigma$ & $1-1$ & 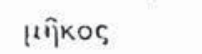 & $2-1$ \\
\hline Tò lepóv & $2-3$ & $\ddot{\omega} p \alpha$ & $2-1$ \\
\hline 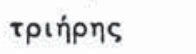 & $1-1$ & $\grave{\eta} \gamma \varepsilon \mu o ́ v \varepsilon \varsigma$ & 1.1 \\
\hline \multirow[t]{2}{*}{ ธvo $\mu \alpha$} & 7.7 & $\dot{\varepsilon} \lambda \pi / \varsigma$ & 2.2 \\
\hline & & Numerales $t$ & el regido $\ldots 13$ \\
\hline
\end{tabular}


De las listas precedentes, el primer hecho que merece ser destacado es que en los ejemplos en los que el regente sigue al genitivo predominan los genitivos pertinentivos o posesivos; por el contrario, en los ejemplos en los que el regente precede al genitivo son amplia mayoría los usos que se pueden clasificar como partitivos o ablativos. Por supuesto, existen algunas excepciones claras en cada grupo, y algunos otros ejemplos son susceptibles de ser clasificados como partitivos o posesivos. Finalmente, en los nombres regentes que preceden o siguen al regido es reducido en ocasiones el número de ejemplos y no permite obtener conclusiones seguras. Entre las excepciones a cada uno de los grupos se pueden identificar ciertas categorías de regentes que presentan determinadas particularidades:

10.1. El nombre regente precede o sigue al regido en varios nombres de género

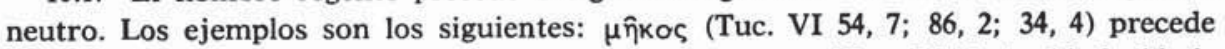
al genitivo dos veces y va detrás una vez; cuatro veces (Tuc. VI 1,$1 ; 15,4 ; 15,4$; Lis. I 1) $\mu \varepsilon \gamma \varepsilon \theta$ os precede al genitivo, y tres veces va detrás (Lis. XXIV 9; And. I $49,107)$, siempre con el nombre regido en posición predicativa; $\pi \lambda \hat{\eta} \theta \circ \varsigma$ precede al genitivo diez veces (Lis. XII 26; 'A $A$. $\pi \circ \lambda$. I 12, III 1, III 6; And. I 107, 135; Tuc. VI 24,$1 ; 31,1 ; 72,4 ; 104,3$ ) y va detrás cinco veces (Tuc. VI 1,$1 ; 19,2$;

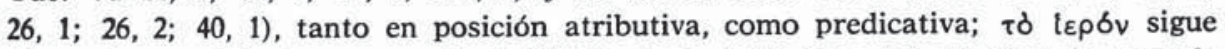
al nombre regido tres veces (Ant. VI 45; And. I 31; Tuc. VI 44, 3) y le precede dos veces (And. I 33; Tuc. VI 46, 3), con alternancia igualmente de posición atri butiva y predicativa; $\tau \dot{\delta} \delta_{v} \mu \alpha$ precede al genitivo en siete ejemplos (And. I 14, $15,25,43,47,78,129$ ) y le sigue igual número de veces (Lis. XII 42; Tuc. VI 54, 6; 64,$2 ; 80,4$; And. I 14, 34, 47), aunque en estos últimos el regido es un relativo o

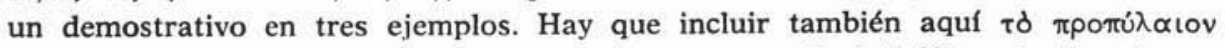

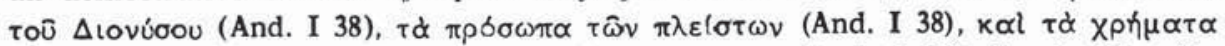

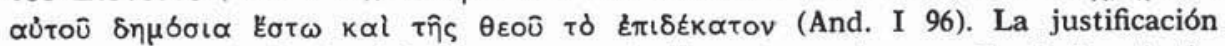
de estas irregularidades debe buscarse probablemente en las peculiaridades sintácticas propias de los neutros; por otro lado, la mayoría de los nombres precedentes comparten ciertos usos sintácticos, el llamado acusativo de relación sobre todo, que podría haber contribuido a un orden de palabras anómalo.

10.2. Un segundo grupo de excepciones está integrado por los numerales cuando siguen al genitivo regido. De las 13 excepciones, diez aparecen en Tucídides VI $(31,2 ; 43,1 ; 43,1 ; 43,1 ; 71,1 ; 71,1 ; 97,4 ; 98,1 ; 98,4 ; 98,4)$, circunstancia que hace verosímil pensar en un hecho específico del historiador. Más notable aún es la semejanza general de los ejemplos, todos ellos dependientes del sujeto gramatical expresado por el numeral (cf. 10.7).

10.3. Algunas otras excepciones aparecen en ejemplos en los que el regente es un genitivo. Además de los ya citados en $\S 5$, § 7, es preciso señalar Ant. VI 22

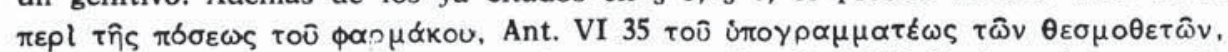

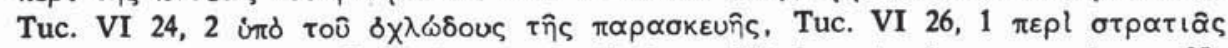

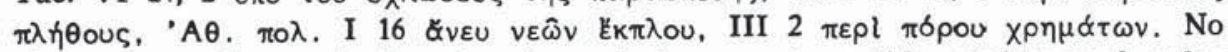
obstante, en algunos de los ejemplos anteriores, es imposible establecer el orden 
habitual de palabras, porque los regentes no aparecen más que una vez en los datos aquí analizados.

10.4. Como es sabido (cf. Schwyzer, II, p. 117 s.), los genitivos que indican la pertenencia a un grupo pueden ser clasificados como partitivos o posesivos. Así

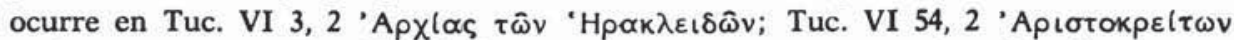

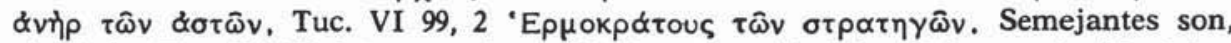

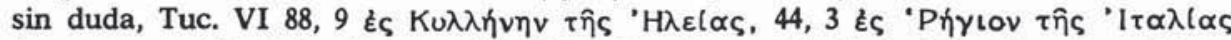

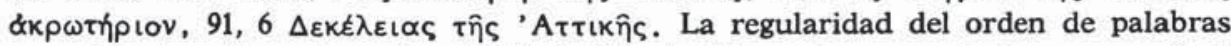
en estos ejemplos y la anteposición habitual del nombre regente hacen verosímil considerar este tipo de genitivos como partitivos, no posesivos, al menos en la lengua de Tucídides.

10.5. Igualmente, es posible que un orden de palabras diferente del habitual indique un tipo de rección distinta del regular o la existencia de determinados hechos contextuales (cf. 7.5).

10.6. Conviene finalmente mencionar ciertas secuencias en las que el orden de palabras manifiesta también gran regularidad, aunque en determinados ejemplos constituyen excepciones al principio de determinación sintáctica del orden de palabras que pretendemos establecer para la prosa literaria ática de circa 400 . Cuando un mismo nombre rige dos genitivos coordinados mediante ơ... \& $\alpha \lambda \alpha$, $\mu \varepsilon v . . . \delta \varepsilon$, el nombre regente aparece con frecuencia entre ambos genitivos; el

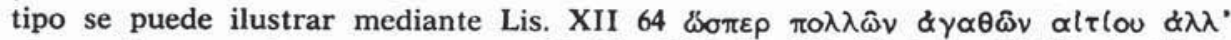

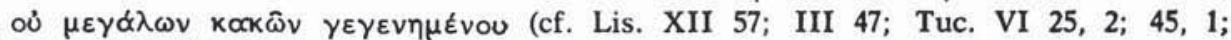
55, 1; Ant. VI 10).

10.7. El genitivo regido suele también preceder a una serie de pronombres y nombres regentes. El tipo se puede ilustrar mediante Tuc. VI 101, $4 \kappa \alpha l \tau \hat{\imath} v$ $\Sigma u p \alpha k o \sigma l \omega v$ of $\mu \dot{\varepsilon} v \ldots$ of $\delta \dot{\varepsilon} \ldots$, y es sobre todo frecuente con of $\mu \dot{\varepsilon} v \ldots$ of $\delta \hat{\varepsilon} \ldots$ (cf. § 5, regla 62) en Tucídides, en cuyo libro VI se pueden identificar al menos 14 ejemplos semejantes. Las excepciones señaladas en 10.2 a propósito de los numerales muestran ciertas semejanzas con estos ejemplos.

También hay que mencionar aquí las expresiones del tipo de Lis. XII 34 suoîv

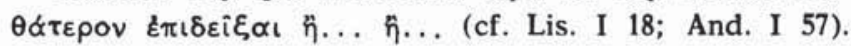

11. Conclusión. Así, pues, el examen de la totalidad de los genitivos adnominales en las obras mencionadas en $\S 2$ muestra que existe una evidente determinación sintáctica en el orden de los elementos, en virtud de la cual el genitivo posesivo suele preceder al regente, y los genitivos no posesivos siguen en general a la palabra regente. Por otro lado, las excepciones pertenecen en su gran mayoría a unos nombres determinados o aparecen en sintagmas especiales, que, a su vez, presentan un orden de palabras regular. Para las restantes excepciones, una causa contextual de carácter enfático es evidente al menos en algunos ejemplos. La determinación sintáctica del orden de palabras no es, sin embargo, 
exclusiva, porque en algunas categorías existe una determinación fonológica o morfológica (cf. 9.1).

Conviene poner de relieve también que, con diferencias menores, el orden de palabras en el grupo de genitivo adnominal-regente, o viceversa, es sensiblemente regular en todos los autores. Este hecho permite asegurar que no se trata de un fenómeno de elección o desviación, sino que el orden de palabras está determinado sintácticamente $\mathrm{y}$, por ello, se puede atribuir a todos los autores que escriben prosa literaria ática circa 400 a. C.

Las diferencias más notables con respecto a los autores restantes aparecen en Tucídides. Además de ciertos sintagmas que son sobre todo o exclusivamente peculiares del historiador, la posición del nombre regido en relación con el artículo del nombre regente muestra irregularidades más usuales que en los demás autores de la época, como se ha visto en 7.8. La tradición historiográfica de ascendencia jonia y el resto de las características propias de la lengua de Tucídides son probablemente la causa de las diferencias con respecto a los demás autores áticos de la época. Por lo demás, como se ha visto, la oposición formal entre posición atributiva y posición predicativa es un fenómeno sumamente reciente, como muestran las inscripciones y algunos ejemplos en la prosa, sobre todo en Tucídides.

Las conclusiones obtenidas del examen del orden de palabras en el grupo de genitivo adnominal y regente tienen ciertas implicaciones importantes que merecen ser señaladas de manera sucinta. Desde el famoso trabajo de J. H. Greenberg ${ }^{25}$ se admite comúnmente la existencia de una estrecha relación entre el orden de palabras regular en las secuencias de determinante-determinado y el orden de objeto-verbo, de suerte que en las lenguas en las que el determinante precede al determinado, el objeto precede al verbo, y viceversa. Si en ático clásico, como hemos visto, el determinante precede al determinado sólo en ciertas condiciones (genitivo posesivo), y el determinado precede al determinante en condiciones también fijas (genitivo partitivo y ablativo), es razonable pensar que el objeto y el verbo no tienen tampoco una posición regular única, sino que el objeto precede al verbo y viceversa sólo en condiciones determinadas. Si esto es así, no es posible admitir que en griego el orden regular es OV o VO; por el contrario, tanto uno como otro orden de palabras son regulares. Sin embargo, es preciso determinar en qué circunstancias es regular OV y en qué otras es regular Vo.

25 Cf. bibliografia citada supra, nota 2 . 
Igualmente, las conclusiones obtenidas afectan de modo importante a la descripción sincrónica del genitivo en griego, porque muestran que existe una característica formal que diferencia genitivo posesivo de genitivo partitivo y ablativo. Además, en determinadas clases el orden de palabras permite clasificar, gracias a la ayuda de este criterio formal, un genitivo como partitivo o posesivo ( $\S 9$ y 10.4). Así, pues, la descripción estructural del genitivo en griego - y lo mismo habría que afirmar acerca de los restantes casos gramaticales para los que se atribuyen significados diferentes- debe tener en cuenta el criterio formal que ofrece el orden de palabras regular.

Emilio Crespo 